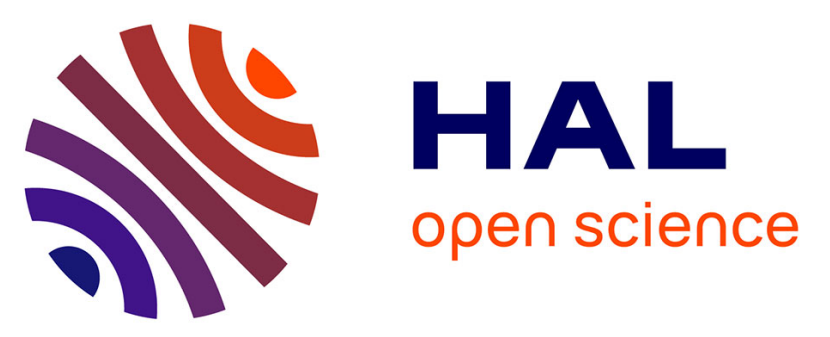

\title{
Live Imaging Reveals Listeria Hijacking of E-Cadherin Recycling as It Crosses the Intestinal Barrier
}

\author{
Minhee Kim, Cindy Fevre, Morgane Lavina, Olivier Disson, Marc Lecuit
}

\section{To cite this version:}

Minhee Kim, Cindy Fevre, Morgane Lavina, Olivier Disson, Marc Lecuit. Live Imaging Reveals Listeria Hijacking of E-Cadherin Recycling as It Crosses the Intestinal Barrier. Current Biology - CB, 2021, 31 (5), pp.1037-1047.e4. 10.1016/j.cub.2020.11.041 . pasteur-03271351

HAL Id: pasteur-03271351

https://hal-pasteur.archives-ouvertes.fr/pasteur-03271351

Submitted on 25 Jun 2021

HAL is a multi-disciplinary open access archive for the deposit and dissemination of scientific research documents, whether they are published or not. The documents may come from teaching and research institutions in France or abroad, or from public or private research centers.
L'archive ouverte pluridisciplinaire HAL, est destinée au dépôt et à la diffusion de documents scientifiques de niveau recherche, publiés ou non, émanant des établissements d'enseignement et de recherche français ou étrangers, des laboratoires publics ou privés.

\section{(ㄷ)(1) $\$$}

Distributed under a Creative Commons Attribution - NonCommerciall 4.0 International 
1 Live imaging reveals Listeria hijacking of E-cadherin recycling as it crosses

\section{2 the intestinal barrier}

5

6

7

$8 \quad{ }^{1}$ Institut Pasteur, Biology of Infection Unit, Paris, France

$9 \quad{ }^{2}$ Inserm U1117, Paris, France

10

${ }^{4}$ Institut Universitaire de France (IUF)

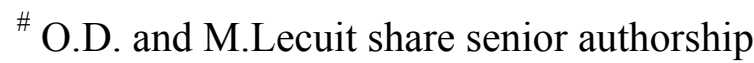

Minhee Kim $^{1,2}$, Cindy Fevre ${ }^{1,2}$, Morgane Lavina ${ }^{1,2}$, Olivier Disson ${ }^{1,2, \#}$, Marc Lecuit ${ }^{1,2,3,4 \#, *}$

${ }^{3}$ Université de Paris, Necker-Enfants Malades University Hospital, Division of Infectious

Diseases and Tropical Medicine, Institut Imagine, APHP, Paris, France

* Corresponding author and lead contact: marc.lecuit@pasteur.fr (M.Lecuit) 


\section{SUMMARY}

Listeria monocytogenes is a foodborne bacterial pathogen that causes human listeriosis, a severe systemic infection [1]. Its translocation across the intestinal epithelium is mediated by the interaction of internalin (InlA), a Listeria surface protein, with its host species-specific receptor E-cadherin (Ecad) [2-5]. It occurs through goblet cells, on which Ecad is luminally accessible [6], via an unknown mechanism. In the absence of cell lines recapitulating this phenotype in vitro, we developed an ex vivo experimental system, based on the intraluminal microinjection of Listeria in untreated, pharmacologically-treated and genetically modified intestinal organoids. Using both live light sheet microscopy and confocal imaging, we show that Listeria translocates through goblet cells within a membrane vacuole in an InlA- and microtubule-dependent manner. As Ecad undergoes constant apical-basal recycling [7, 8], we hypothesized that $L m$ may transit through goblet cells by hijacking Ecad recycling pathway. Indeed, Listeria is stuck at goblet cell apex when Ecad endocytosis is blocked, and remains trapped intracellularly at the basolateral pole of goblet cells when Rab11-dependent Ecad recycling is compromised. Together, these results show that Listeria, upon docking onto its luminally accessible receptor Ecad, hijacks its recycling pathway to be transferred by transcytosis across goblet cells. Live imaging of host-pathogen interactions in organoids is a promising approach to dissect their underlying cell and molecular biology.

\section{Keywords}

Listeria, epithelial translocation, organoids, intestine, goblet cell, E-cadherin recycling, live imaging, Rab11 


\section{RESULTS AND DISCUSSION}

In order to decipher the cell biology mechanisms of Listeria translocation across the intestinal epithelium, we developed a genetically amenable experimental system permissive to InlAEcad-dependent trans-epithelial crossing. Deciphering the detailed cell biology mechanisms of Listeria translocation across the intestinal epithelium in vivo would require interfering with cellular pathways that may disrupt its barrier function. Additionally, it would be extremely challenging to capture Listeria translocation in real-time across intestinal villus epithelium, given its rarity and intestinal peristalsis. Furthermore, no adherent cell, including human colonic cell lines T84, HT29 and Caco-2, displays an apical-basal polarization and apical accessibility of Ecad, which are both critical for Listeria InlA-Ecad-dependent trans-epithelial crossing to occur (our unpublished observations). We therefore set up an ex vivo experimental system based on the microinjection of Listeria in the lumen of intestinal organoids. Intestinal organoids derive clonally from intestinal stem cells, which give rise to a fully differentiated, polarized intestinal epithelium that forms a so-called "minigut" centered by a lumen, and contains differentiated intestinal cell subtypes [9]. Intestinal organoids are genetically amenable [10-13], can be subjected to pharmacological interventions [14], and can also be imaged both fixed and alive $[9,15]$.

\section{Intestinal organoids contain goblet cells}

We generated intestinal organoids from the small intestine of knock-in E16P (E16P KI) mice, in which the endogenous mouse Ecad is punctually modified to express a proline at position 16 of the mature protein in place of a glutamic acid. This modification enables this "humanized" mouse Ecad to interact with InlA and mediate Listeria internalization $[1,4,16]$ (see Methods). As expected [9], E16P organoids grown in Matrigel ${ }^{\circledR}$ exhibit a fully mature apical-basal polarity and display cell subtype heterogeneity. Organoids intestinal stem cells differentiate into enterocytes $\left(\right.$ Villin $\left.^{+}\right)$, enteroendocrine cells $\left(\right.$Chromogranin $\left.A^{+}\right)$, goblet cells $\left(\mathrm{WGA}^{+} /\right.$Lysozyme $\left.^{\text {low }}\right)$ and Paneth cells $\left(\mathrm{WGA}^{\text {low }} /\right.$ Lysozyme ${ }^{+}$, Figure S1A). Additionally, and as previously reported [17], intestinal organoids do not contain M cells (GP2 ${ }^{+}$) (Figure S1A). As Listeria cross the intestinal barrier via goblet cells in vivo, it is important to unambiguously identify this cell subtype in our experimental model. Goblet cells are mucussecreting cells with a characteristic goblet-shaped cell morphology, which nucleus location does not align with neighboring enterocytes [18]. Additionally, goblet cells can be identified by immunolabeling of the Muc2 mucin, a major mucus component, following Carnoy hydrophobic fixation [19]. However, Muc2 labeling cannot be applied to our experimental 
system: Carnoy fixation damages plastic wells in which Matrigel ${ }^{\circledR}$ embedded organoids are located, and more importantly, renders Matrigel $\mathbb{R}$ opaque. Therefore, we used wheat germ agglutinin (WGA), which labels mucus by binding to sialic acid and N-acetyl-glucosaminyl carbohydrate residues on mature, modified mucins [20, 21]. WGA positive cells were colabeled for cytokeratin-18, which is specifically expressed in goblet cells in the gut [22] (Figure S1B). Of note, PFA fixation can dissolve mucus, resulting in bona-fide WGAnegative goblet cells. Therefore, we used the following criteria to identify goblet cells: $(i)$ WGA labeling, (ii) goblet-shaped cellular morphology, and (iii) misaligned nucleus relative to neighboring cells. When WGA-negative cells strictly met the last two conditions, we also considered them as goblet cells (e.g., in Figure S1D right).

\section{Listeria translocation across intestinal organoid goblet cells requires InlA}

We microinjected $5 \times 10^{3}$ CFUs of wild type $L m$ into the lumen of mature organoids and investigated bacteria interactions with the intestinal epithelium (Figure 1A). Confocal imaging of intestinal organoids fixed 1 hour after microinjection allowed the detection of bacteria both inside and underneath the basolateral pole of goblet cells (Figure 1B, Video S1). Quantification studies 16 hours post-infection revealed that bacteria were all located exterior to microinjected organoids, specifically associated with goblet cells, as a result of translocation events (Figure 1C). Of note, the microinjection procedure and/or presence of bacteria in the organoid lumen did not modify the proportion of $\mathrm{WGA}^{+}$cells $(10.87 \pm 3.07 \%)$ compared to non-injected organoids $(9.56 \pm 2.62 \%$, Figure S1C). Consistent with our previous in vivo studies in humanized mice permissive to InlA-Ecad interaction $[5,6,16]$, this phenotype was strictly InlA-dependent. In contrast, it was independent of LLO and ActA, which mediate $L m$ escape from its internalization vacuole and actin-based motility, respectively (Figure 1C). Li(InlA) is derived from L. innocua, a non-pathogenic Listeria species devoid of L. monocytogenes virulence factors, which has been genetically modified to express InlA, and enters into cells in an Ecad-dependent manner [23]. Upon microinjection in intestinal organoids lumen, $L i(\operatorname{Inl} \mathrm{A})$ was also located extracellularly at basolateral pole of goblet cells, as wild type $\mathrm{Lm}$ (Figure 1C, Figure S1D,E, Video S1). This indicates that Listeria crossing of the intestinal epithelium does not require escape from the vacuole and actin-based motility. In some cases, bacteria underneath goblet cells were surrounded with WGA-labeled material, implying that bacteria can translocate with mucus (Figure S1E). Of

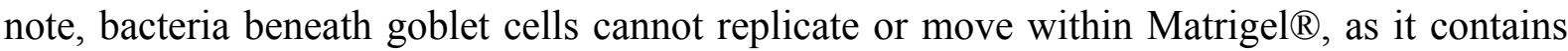
gentamicin and is bactericidal. Together, these results show that Listeria microinjection in the 
lumen of intestinal organoids allows to faithfully recapitulate Listeria translocation across the intestinal epithelium in vivo. These results also confirm that InlA is necessary and sufficient to mediate Listeria translocation across goblet cells, while LLO and ActA are dispensable [6], and justify the use of $L i(\operatorname{In} 1 \mathrm{~A})$ for further experiments, in order to minimize the potential cytotoxicity of LLO to microinjected organoids [24].

\section{Real-time imaging of Listeria transcytosis across intestinal organoid epithelium}

Despite converging evidences indicating that Listeria transcytoses through goblet cells in vivo [6], live imaging has not been performed to prove it actually occurs, i.e. translocation of a bacterium surrounded by its internalization vacuole. We therefore set up experimental conditions to image in real time translocation of $L i$-GFP(InlA) across intestinal organoids in which cell membranes are constitutively red fluorescent (mtd-Tmt; E16P KI). Listeria translocation across the intestinal epithelium is a rare event in vivo, as only 3 to $4 \%$ of intestinal villi are infected in 45 minutes long intestinal ligated loop assays (our unpublished observation). Moreover, $L m$ translocation across the small intestinal epithelium occurs within 30 minutes in vivo [6]. The rarity of translocation events requires that entire organoids are scanned to be captured, and this may exceed the time needed for bacterial translocation when using classical confocal imaging. Additionally, laser power has to be minimal to preserve the fluorescence signal of individual bacteria and cell membrane over prolonged imaging. Furthermore, imaging has to be performed at the adequate spatial resolution to track micronsized bacteria within intestinal organoids, the diameter of which ranges from hundreds to thousands of microns. To accommodate all these experimental requirements, light sheet microscopy was used, which can image intestinal organoids at least thirty times faster than a regular confocal microscope with minimal phototoxicity. $5 \times 10^{3}$ CFUs of $L i$-GFP(InlA) were microinjected intraluminally into mtd-Tmt; E16P KI organoids. Real time imaging revealed that a bacterium reached cell basolateral pole surrounded by a cell membrane in less than 12 minutes. During the following 36 minutes, the bacterium remained at the basolateral pole of the cell, surrounded by mtd-Tmt signal, and then exited from the cell basolaterally (Figure 1D, Video S2). This allowed to image for the first time Listeria transcytosis across the intestinal epithelium directly and unambiguously.

\section{Ecad is luminally accessible on goblet cells in intestinal organoids}

InlA-dependent translocation of Listeria specifically through goblet cell (Figure 1B,C, Figure S1D,E) suggests that translocation is mediated by InlA interaction with luminally accessible 
Ecad on goblet cells, as it has been observed in vivo [6]. To assess luminal accessibility of Ecad in organoids, we applied an Ecad antibody directed against its ectodomain (ECCD-2) to the accessible luminal side of fixed and sectioned organoids (Figure 1E). To stain only accessible Ecad, we performed surface immunolabeling without cell permeabilization. Junctional proteins in the sectioned plane are exposed, accessible without permeabilization, and are therefore also labeled. However, junctional proteins located below the cutting plane cannot be labeled in the absence of cell permeabilization, unless they are inherently luminally accessible (Figure 1E,F). As expected given the specific location of InlA-Ecad Listeria translocation (Figure 1C), luminally accessible Ecad was detected only on the apical side of mucus-expelling goblet cells in non-permeabilized organoids (Figure 1E, Video S3). In contrast, in permeabilized organoids, Ecad was detected at adherens junctions, down to the basolateral membrane in all cells regardless of the subtype (Figure 1F, Video S3). Together, these results indicate that the cells on which Ecad is luminally accessible in intestinal organoids are mucus-expelling goblet cells, and that bacteria located beneath the basal pole of goblet cells after intraluminal microinjection have undergone InlA-Ecad-mediated transcytosis. This establishes the specificity of this ex vivo experimental system to study the cell biology of Listeria InlA-Ecad translocation across the intestinal epithelium.

\section{Endocytosis and microtubule dynamics are required for Listeria translocation through goblet cells}

Previous in vivo investigations have shown that InlA-Ecad-dependent Listeria crossing of the intestinal barrier depends on microtubule and the exocytic machinery [6]. We therefore hypothesized that Listeria, upon its docking on luminally accessible Ecad on goblet cells, hijacks Ecad recycling pathway to cross the intestinal epithelial barrier, from its dynaminmediated endocytosis [7] and endosomal trafficking along microtubules [25], to its Rab11 dependent release at the cell basolateral pole [26, 27]. Ecad recycling has not been studied in goblet cells, but it is also expected to involve its endocytosis at the apical pole and basolateral recycling in a microtubule-dependent manner. We therefore tested this hypothesis by dissecting the role of Ecad recycling pathway on Listeria transcytosis.

In polarized differentiated cells, Ecad, which forms adherens junctions (AJ), is endocytosed in a clathrin-dependent manner [7]. The resulting endosomes are excised from the plasma membrane by the GTPase dynamin $[28,29]$. Ecad is trafficked in a microtubule-dependent manner [25, 30, 31] and recycled to the basolateral membrane [7]. To first inhibit Ecad endocytosis, we used dynasore, a dynamin inhibitor that prevents the fission of clathrin- and 
caveolin-dependent endocytic vacuoles [32, 33]. To inhibit microtubule-based Ecad trafficking, we used colchicine, which blocks microtubule polymerization. In organoids treated 2 hours with dynasore, cytosolic endocytic Ecad punctae were drastically reduced (Figure S2C), as previously reported in cultured cells [29]. In presence of colchicine, more cells with metaphase-blocked mitoses were observed (Figure 2A) as expected [34], indicating that both drugs are active in our system. Nevertheless, the overall morphology and polarity of the organoids were comparable to non-treated controls (Figure 2A) and we observed no difference in total bacterial association to cells (either apically, intracellularly or basolaterally) (Figure 2B). Yet there was a significant decrease of extracellular translocated bacteria in dynasore- and colchicine-treated organoids, relative to control organoids (Figure 2C). Consistent with a similar total bacterial association to cells in all conditions, accessible Ecad was detected similarly on goblet cells in dynasore- and colchicine-treated conditions (Figure 2D, Figure S2, Video S4), as in untreated organoids (Figure 1E). This suggests that the interaction between Listeria and its receptor Ecad is not impaired in dynasore- and colchicinetreated organoids, whereas Listeria transcellular transport is blocked within goblet cells. To examine where bacteria were trapped in cells, we investigated their location in three distinct compartments: apically associated to the cell membrane, intracellular, and extracellular at their basal pole. In dynasore-treated organoids, bacteria were mostly apically associated (Figure 2C,E dynasore, Figure S3, Video S4). These bacteria were likely trapped in elongated invaginations of the plasma membrane, as observed both in Drosophila and mammalian epithelial cells when dynamin is inhibited [35-37]. In colchicine-treated organoids, where microtubule dynamics is inhibited, intracellular bacteria were located in the median part of the cells (Figure 2C,E colchicine, Figure S3, Video S4). In all experimental conditions, intracellular bacteria were surrounded with Tomato red-labelled membrane, indicating that bacteria were within a vacuole (Figure 2E). Together, these results show that upon InlAmediated Listeria docking to Ecad, Ecad endocytosis is required to complete bacterial internalization into goblet cells, and microtubules dynamics is required for bacterial transepithelial transit in a vacuole.

\section{Rab11 is required to complete Listeria intestinal translocation through goblet cells}

We next investigated whether recycling of Ecad endosomes is required for Listeria InlAdependent translocation across the intestinal epithelium. Ecad is recycled and trafficked via Rab11-positive recycling endosomes, which recruit the exocytosis machinery $[8,26,27,38$, 39]. Rab11 is also involved in basolateral sorting of newly synthesized Ecad in polarized 
mammalian cells in vitro [38]. The kinetics of Rab11-based trafficking is around 30 minutes [40, 41], which fits with our live imaging of Listeria crossing the epithelium (Figure 1D and Videos S2). Therefore, to perturb Ecad recycling, we targeted Rab11. Since Rab11 null mutations are embryonically lethal in mice $[42,43]$ and constitutive knock-out of Rab11 may be detrimental for the development of intestinal organoids, we generated lentivirus-transduced organoids in which a dominant negative and myc-tagged version of Rab11 can be induced by doxycycline. As Rab7-dependent Ecad degradation pathway [44] is not expected to be involved in bacterial translocation, we also generated lentivirus-transduced organoids in which a dominant negative Rab7 can be induced, to use them as negative controls. To visualize successful transduction and transcription induction, we used a bi-cistronic reporter system where an internal ribosome entry site (IRES) is placed downstream of each DN mutant and upstream of a mCerulean coding sequence (Figure 3A,B). Organoids were grown and maintained in presence of antibiotics to select for transduced cells. When organoids were properly formed and mature, doxycycline was added 12-16 hours before microinjection to induce the transcription of dominant negative Rab11 and Rab7 variants Rab11DN and Rab7DN, respectively (Figure 4A). Organoids expressing Rab11DN exhibited cytosolic Ecad punctae that accumulated at basolateral side of epithelial cells compared to control organoids, consistent with a blockade of Ecad release when Rab11 is non-functional (Figure S2C). Induced expression of Rab7DN caused general enrichment of cytosolic Ecad (Figure S2C), and large Ecad aggregates formed throughout the apical-basal axis (Figure S2C), suggesting that Ecad degradation is affected when Rab7 is non-functional [44]. However, inducing Rab11 and Rab7 dominant negative proteins for a short period of time (less than 24 hours) did not detectably impair epithelium morphology (Figure 3C) and Ecad luminal accessibility compared to WT organoids (Figure 4B, Figure S2, Videos S5).

Microinjection experiments revealed that induction of Rab7DN did not affect bacterial translocation through goblet cells. Listeria was found extracellular at the basolateral pole of goblet cells of Rab7DN-induced organoids, to the same degree than in transduced but noninduced control organoids (NI). This shows that bacteria complete translocation normally within goblet cells in presence of Rab7DN (Figure 4C-E Rab7DN, Figure S3, Video S5). In contrast, in mycRab11DN-induced transduced organoids, a significant decrease of translocated bacteria beneath goblet cells was observed, together with a corresponding significant increase of intracellular bacteria. Intracellular bacteria were mostly located at the basolateral pole of goblet cells (Figure 4C-E Rab11DN, Figure S3, Video S5). This was also the case for wild type Listeria microinjected in mycRab11DN-induced organoids, even 16- 
hour post microinjection (Figure S2D-F). Note that prolonged exposure to doxycycline might have prevented Listeria vacuolar escape and cell-to-cell spread at this late time point. Taken together, these data show that Rab11, in contrast to Rab7, is required for the release of bacteria from the basal pole of goblet cells, highlighting that Listeria hijacks Rab11dependent Ecad recycling for trans-epithelial translocation via goblet cells.

\section{Organoid as a model for real-time investigation of host-pathogen interactions}

Here, we have developed an ex vivo minigut system in which Listeria crosses the intestinal barrier by transcytosis through goblet cells as it does in vivo [6]. We have harnessed the power of this experimental system to directly image, in real time, the trans-epithelial translocation of a microbial pathogen, and to dissect the underlying cell biology and molecular mechanisms. Listeria crossing of the intestinal barrier relies on the specific interaction of InlA with luminally accessible Ecad at the apical pole of goblet cells. We have shown that $(i)$ bacterial Ecad-dependent internalization in goblet cells requires dynaminmediated endocytosis, (ii) bacteria transit through these cells in a microtubule-dependent manner as in vivo [6], and (iii) Rab11 is required for the release of Listeria at the basolateral pole of goblet cells, thereby showing that Listeria hijacks E-cadherin recycling pathway to cross the intestinal barrier (Figure S3). While organoids have been used to investigate infection with human norovirus and SARS-CoV-2 [45, 46], and the interactions of enteropathogens such as Salmonella enterica [47] and Cryptosporidium parvum with the intestinal epithelium [48], here we have microinjected for the first time microbes in the lumen of intestinal organoids, imaged in real time microbial crossing of the intestinal barrier, and deciphered the underlying molecular mechanisms of microbial translocation. This novel ex vivo system of infection opens a wide range of opportunities to study pathogen interactions with host barriers in a direct manner, in contrast to what has been done so far. Additionally, this study also pioneers the use of genetically modified inducible organoids to address the cellular and molecular mechanisms of host-pathogen interactions in a tissue context. Rab11 has been shown to be necessary for Ecad recycling in mammalian cells and in vivo in Drosophila melanogaster [8]. Moreover, Rab11 is required for basolateral trafficking of newly synthetized Ecad in polarized MDCK cells [38]. However, the cellular trafficking of Ecad from its apical to basolateral pole from either side of adherens junctions had not been thoroughly investigated in a tissue context to our knowledge. It has been previously shown in non-polarized epithelial intestinal Caco-2 and trophoblastic JEG3 cell lines that, upon binding of InlA to Ecad, the plasma membrane is remodeled in an actin-dependent manner and leads 
to caveolin- and clathrin-dependent bacterial endocytosis [32, 49-53]. In cultured epithelial cells, Listeria internalization occurs mainly at the edge of cell islets, where cells are nonpolarized and Ecad is broadly accessible. Once internalized into these non-polarized cells, $\mathrm{Lm}$ escapes from the vacuole in an LLO dependent manner and propels itself through ActA in the cytosol [54]. Here, we have shown that in polarized differentiated goblet cells in a tissue context, the initial step of internalization through accessible Ecad is also dynamin-dependent. However, after completing bacterial internalization, $\mathrm{Lm}$ is rapidly transferred and released to the basolateral pole of goblet cells, owing to the rapid Rab11-dependent recycling of Ecad. This may protect invading bacteria from epithelial innate immune responses and favor their dissemination in host tissues. Live imaging of host-pathogen interactions in organoids is a promising approach to dissect their underlying cell and molecular biology. 


\section{Acknowledgements}

We thank Dr. Thaddeus Stappenbeck, Washington University in Saint Louis, USA and Corinne Lebreton, Institut Imagine, Paris, France for the L-WRN cell line. We thank Miranda Vogt, Stanford University, USA, for her contribution to this study as a summer student. We thank for the help of Image Analysis Hub of the Institut Pasteur and the members of Biology of Infection Unit for their support. Minhee Kim received a long-term postdoctoral fellowship from the European Molecular Biology Organization (EMBO), ALTF 1192-2017. Institut Pasteur, Inserm, LabEx IBEID, the European Research Council (ERC) Invadis and ANR Organolist provided financial support.

\section{Authors' contributions}

M. Lecuit conceived the project, designed the study, directed the research and edited the manuscript. M.K. designed and performed experiments, analyzed data and wrote the manuscript. C.F. designed and performed some experiments and analyzed some of the data. M. Lavina provided technical help. O.D. participated in the supervision of the study, data analysis and writing \& editing of the manuscript.

\section{Declaration of interests}

The authors declare that there is no competing financial interest in this study. 


\section{Figure 1. Ex vivo intestinal organoid model of Listeria infection}

(A) Experimental scheme and example of Listeria microinjection (details in the Methods). (B) Example images of Listeria translocation (optical section). $L m$ within a goblet cell, fixed 1 hour post microinjection (left panel; goblet cell marked with an arrow). $\mathrm{Lm}$ basolaterally extracellular beneath a goblet cell (right panel; goblet cells are marked with arrows). See also Video S1. Translocated bacteria were distinguished from the total bacteria by consecutive immunostaining, first against $\mathrm{Lm}$ without permeabilization followed by tissue permeabilization and labeling (Method). Scale bars, $10 \mu \mathrm{m}(\mathbf{C})$ Quantification of Listeria translocation. Top: Number of cells associated with bacteria either intracellularly or basolaterally extracellularly per organoid. Bottom: Number of translocated bacteria per organoid. Counts were performed in 12 organoids for each condition. Two-Way ANOVA test. NS: Not significant; $* * * *: p<0.0001$. See also Figure S1D,E, Video S1. (D) Light sheet live imaging at indicated time point (top, maximum intensity projection (MIP); bottom, optical section). Within 12 minutes, bacteria-containing vesicle reaches the basolateral side of the cells, then exit from the cell in the following time points. Intracellular Listeria is surrounded with membrane tomato (arrow). See also Video S2. (E) Left: Scheme depicting detection of luminally accessible Ecad from side and top view. Organoids were fixed, embedded, sectioned to open the lumen and immunolabeled from the luminal side without permeabilization. Ecad in the sectioned plane is exposed, thus accessible without permeabilization and stained throughout the cutting plane (marked with green on the drawing). Right: 3D-view of opened organoids from the side (top left) and top (bottom left). Enlargement of boxed area on the left 3D-reconstructed organoids containing goblet cells expressing luminally accessible Ecad (center \& right). Mucus that has been expelled is marked with WGA conjugated with fluorophore. Accessible Ecad surrounds the expelled mucus. Scale bars, $10 \mu \mathrm{m}$. See also Video S3. (F) Left: Scheme depicting detection Ecad from side and top view. Organoids were fixed, embedded, sectioned to open the lumen, permeabilized and immunolabeled from the luminal side. Total Ecad is stained (marked with green on the drawing). Right: 3D-view of opened organoids from the side (top left) and top (bottom left). Enlargement of boxed area on the left 3D-reconstructed organoids containing goblet cell (center \& right). Scale bars, $10 \mu \mathrm{m}$. See also Video S3. 
Figure 2. Endocytosis and microtubule dynamics are required for bacterial translocation

(A) Top: Experimental scheme of microinjection. Bottom: Confocal imaging of permeabilized, whole-mount stained organoids treated with indicated inhibitors. In cholchicine treated organoids, epithelium displayed more metaphase-blocked cells (+, enlarged), indicating that cholchicine treatment worked (B) Quantification of number of cells associated with bacteria. (C) Quantification of number of bacteria per organoid in indicated location. Experiments were repeated 2 to 3 times. The results combine all experiments. 27 WT \& dynasore-treated organoids and 21 colchicine-treated organoids were counted. Kruskall Wallis test. Comparison to WT. NS: Not significant; *: $\mathrm{p}<0.5 ; * *: \mathrm{p}<0.01 ; * * * *: \mathrm{p}<0.0001$. See Also Figure S3. (D) Accessible Ecad from the luminal side of the sectioned organoids treated with indicated inhibitors. See also Figure S2, Video S4. (E) Confocal images of bacteria trapped inside the goblet cells in each condition (optical section from 3D reconstruction, goblet cells are marked with an arrow). Bacteria are located in apical and central side within the cells in dynasore- and cholchicine-treated conditions, respectively. Bacteria are surrounded with a tomato-stained membrane. See also Figure S3 and Video S4. 
Figure 3. Inducible organoids expressing dominant-negative Rab11 and Rab7

(A) Scheme depicting the organoid transduction. (B) Visualization of successful induction with Dox for 16 hours. mCerulean (mCer) expression was detected by eyes using Zeiss Filter set 38 HE (excitation BP 470/40, beamsplitter FT 495, emission BP 525/50). (C) Confocal imaging of permeabilized, whole-mount stained organoids induced with indicated DN proteins for 16 hours with Dox. Expression of DN proteins is visualized by anti-Rab7 (Rab7DN) or anti-myc (Rab11DN) staining. In mycRab11DN-induced organoids, mCer colocalized with myc staining (not shown). Goblet cell producing mucus are labeled with WGA (arrow). Junctional integrity of organoids is evaluated by Ecad staining. 


\section{Figure 4. Listeria translocation requires functional Rab11 but not Rab7}

(A) Experimental scheme of microinjection. The organoids were grown in presence of antibiotics (penicillin-streptomycin, geneticin and puromycin) and doxycycline was added 1216 hours before the microinjection. Induction of mCer was detected by eyes with Zeiss Filter set 38 HE (excitation BP 470/40, beamsplitter FT 495, emission BP 525/50, Figure 3B). Induced organoids were selected and microinjected, incubated for 2 hours (DN proteins still being induced) followed by fixation \& imaging. (B) Luminally accessible Ecad of the sectioned organoids induced with indicated DN proteins. Accessible Ecad staining in XY, XZ and YZ planes from indicated goblet cells (arrow from the right 3D reconstruction, sectioned plane facing up in the side view). See also Video S5. (C) Optical sections from 3D reconstruction of microinjected organoids induced for indicated DN proteins. $L i$-GFP (InlA) can be detected beneath the basolateral side of the goblet cells in transduced, but non-induced control (top) and in Rab7DN-induced organoids (center), indicating that bacterial translocation occurred. $L i$-GFP (InlA) is trapped at the basal pole of the goblet cell, embedded in $\mathrm{WGA}^{+}$material in mycRab11DN-induced organoids (bottom). Goblet cells are marked with an arrow. Scale bars, $20 \mu \mathrm{m}$. See also Figure S3 and Video S5. (D) Quantification of number of cells associated with bacteria per organoids. Kruskall Wallis test. Comparison to WT. NI: Lentivirus transduced, non-induced control. NS: not significant. (E) Quantification of number of bacteria per organoid in indicated location. Experiments were repeated 2 to 3 times. The results combine all experiments. Counts were performed in 19 non-induced, 18 Rab7DN and 24 Rab11DN organoids. The results for WT organoids are those from Figures 2B,C. Kruskall Wallis test. Comparison to WT. NS: Not significant; *: $\mathrm{p}<0.05 ; * *$ : $\mathrm{p}<0.01$. See also Figure S3. 
STAR Methods

\section{RESOURCES AVAILABILITY}

\section{Lead Contact}

Further information and requests for resources and reagents should be directed to and will be fulfilled by the Lead Contact, Marc Lecuit (marc.lecuit@pasteur.fr).

\section{Materials Availability}

All plasmids generated in this study are available upon request.

\section{Data and Code Availability}

This study did not generate/analyze datasets or codes

\section{EXPERIMENTAL MODEL AND SUBJECT DETAILS}

\section{Bacteria}

For Figure 1B-C, Lm strain EGD (BUG 600) and isogenic deletion mutants $\triangle i n l A$ (BUG 947 [56]), $\Delta h l y$ (BUG 2132 [57]), $\Delta a c t A$ (BUG 2140 [57]), Li WT (BUG 499), Li-expressing InlA ( $L i$ (InlA+), BUG 1489 [23]) were used. We generated $L i$-expressing both InlA and GFP in tandem under the phyper promoter of $\mathrm{pAD}$ vector, separated by the terminator sequence (MBHL 366). Bacteria were transformed by electroporation. GFP expression was confirmed by fluorescent microscopy, function of InlA was confirmed by in vitro invasion assay using mouse fibroblast L2071 expressing human E-cadherin[49].

\section{Mice}

E16P KI mice were generated in the laboratory [16]. They were crossed with $\mathrm{mT} / \mathrm{mG}$ mice [59] to generate mtd-Tmt; E16P KI mice. Animal experiments were performed according to the Institut Pasteur guidelines for laboratory animals' husbandry and in compliance with European regulation 2010/63 EU. They were approved by the ethical committee CETEA/CEEA No. 89 of Institut Pasteur under the number DHA180011.

\section{Organoids}


Intestinal organoids were generated and cultured from the crypts recovered from small intestines of 6- to 8-week old KIE16P and mtd-Tmt; E16P KI mice using EDTA dissociation method $[9,60]$. They were grown in ENR medium (Advanced DMEM/F12 with EGF (50 $\mathrm{ng} / \mathrm{ml})$, Noggin (100 ng/ml) and R-spondin1 (500 ng/ml)).

\section{Cells}

HEK293T cells (ATCC CRL-11268) were grown and passaged in DMEM containing 2\% glutamine, 10\% Tet-system approved FBS (Takara \# 631106) and penicillin-streptomycin.

\section{METHOD DETAILS}

\section{Organoid microinjection}

Mature organoids growing in ENR medium were mechanically dissociated and passed into the gridded, low-bottom iBidi-injection plate (Clinisciences \# 80156). Result of Figure 1B-C was obtained with ENR medium while all others were obtained using the following condition: Organoids were passed in injection plates with 2:1 ratio of ENR and 50\% of L-WRN cellconditioned media (made with Tet System Approved FBS, Takara \# 631106) for 1-2 days to have a round center to facilitate microinjection. When the organoids produced spherical centers, the organoids were washed several times with pre-warmed Advanced DMEM/F12 to remove the serum and excessive growth factors, replaced with either ENR or 5\% L-WRN conditioned media for minimal 1 day. A day before the microinjection, $10 \mu \mathrm{M}$ DAPT and 20 $\mu \mathrm{g} / \mathrm{ml} \mathrm{IL-13}$ were supplemented overnight to partially enrich the goblet cells and to induce mucus expel from the existing goblet cells [61-63]. Figure 2A, final concentration of $80 \mu \mathrm{M}$ dynasore or $10 \mu \mathrm{g} / \mathrm{ml}$ colchicine were applied 2 hours prior to microinjection. Figure $4 \mathrm{~A} \& \mathrm{C}$, final concentration of $2 \mu \mathrm{g} / \mathrm{ml}$ doxycycline was added to the media 12-16 hours before the microinjection. Microinjection was performed only to organoids verified to have successful induction. Results of Figure 1B-C were obtained by fixing 1 hour and 16 hours, respectively, after microinjection. The incubation period post microinjection of the other experiments was optimized to 2 hours followed by fixation to reduce the damage of the organoids. Drug/doxycycline treatment was maintained during this period. For live imaging, immediately after microinjection, organoids were re-sampled to the imaging chamber of light sheet microscope Zeiss Z1.

Overnight culture of bacteria was diluted (1/200) and grown until O.D 0.8, washed at least 3 times in PBS and collected as a final volume of $100 \mu \mathrm{l}$ in DMEM/F12 phenol red-free 
medium. Microinjection was performed with Eppendorf InjectMan and FemtoJet system as reported [64] using glass micropipettes injection needle (Vitromed \# V-INJ-S3-35).

\section{Accessible Ecad detection}

Organoids were passed on the 8-well Lab-Tek plates and supplied with the media as for the microinjection: first with 2:1 ratio of ENR and 50\% L-WRN cell conditioned media to grow the spherical center, followed by washing and either returned to ENR media or supplied with 5\% L-WRN media for at least 1 day. A day before the fixation, organoids were treated at a final concentration of $10 \mu \mathrm{M}$ DAPT and $20 \mathrm{ng} / \mathrm{ml}$ IL-13 overnight to induce mucus expel from the existing goblet cells. Organoids were fixed with $4 \%$ PFA at $4{ }^{\circ} \mathrm{C}$ overnight. For the experiments in Figure 2D, final concentration of $80 \mu \mathrm{M}$ dynasore or $10 \mu \mathrm{g} / \mathrm{ml}$ colchicine were added 2 hours before fixation. Experiment of Figure 4B, final concentration of $2 \mu \mathrm{g} / \mathrm{ml}$ doxycycline was added 12-16 hours before fixation. When the organoids were fixed, PFA was removed, organoids were washed and 6\% low-melting agarose was poured to the wells. Solidified wells were recovered, sectioned in 150-200 $\mu \mathrm{m}$ thickness with a vibratome (Micro HM 650V, Thermo Fisher Scientific). Sections containing opened organoids were blocked in $3 \%$ BSA in PBS and stained as indicated below.

\section{Immunofluorescence}

Accessible Ecad (Figure 1E, 2C and 4B): Organoids were fixed with 4\% PFA at $4^{\circ} \mathrm{C}$ overnight followed by washing and blocking with 3\% BSA in PBS, overnight at room temperature. Primary and secondary antibodies were applied for 1 hour at room temperature.

Whole-mount staining: Organoids were fixed with 4\% PFA for $30 \mathrm{~min}-1$ hour at room temperature followed by washing, blocking/permeabilizing for 2 hours either in 5\% goat serum with $1 \%$ Triton $\mathrm{X}-100$ or in $3 \%$ BSA with $1 \%$ Triton X-100 in PBS. Primary antibodies were applied at $4{ }^{\circ} \mathrm{C}$ overnight followed by washing and stained with secondary antibodies for 2 hours at room temperature or $4^{\circ} \mathrm{C}$ overnight.

Distinguishing intracellular vs translocated bacteria (Figure 1B): Organoids were fixed with $4 \%$ PFA at $37^{\circ} \mathrm{C}$ for 1 hour, washed and blocked without triton for 2 hours at room temperature. Rabbit antisera against Listeria monocytogenes (R11 [55]) was added for 2 hours at room temperature, followed by washing and secondary antibody for 1 hour at room temperature to stain extra-organoid bacteria. Then microinjected organoids were 
permeabilized with $1 \%$ Triton $\mathrm{X}-100$ and stained with primary antibody at $4{ }^{\circ} \mathrm{C}$ overnight followed by washing and secondary antibody for 2 hours at room temperature.

The following antibodies were used: anti-Ecad (Eccd2, Takara \#M108, 1:350), anti-myc (71D10, Cell Signaling \# 2278, 1:500), anti-Rab7 (Sigma, \#R4779, 1:200), WGA conjugated with alexa 647 (Invitrogen, whole mount 1:300, section 1:1000) and Hoechst 33342 (Invitrogen 1:5000). Secondary antibodies include goat anti-rat conjugated with alexa 546, goat anti-mouse conjugated with alexa 405, and goat anti-rabbit conjugated with alexa 405 (all Invitrogen 1:500). To identify the goblet cells, the following criteria were used, as the Muc2 labeling method following Carnoy fixation and paraffin embedding [65] is not compatible with our system, rendering the matrigel opaque as well as breaking the plate: $\mathrm{WGA}^{+}$, typical goblet-shaped cellular morphology including the opening of the apical area and the nucleus misaligned with neighboring cells. If the cells meet 2 or more conditions, we regarded them as goblet cells.

\section{Imaging}

Images were acquired either by confocal microscope (fixed image, upright Zeiss LSM 700 equipped with a water Plan-Apochromat 40x/1.0 DIC M27 objective \& inverted Zeiss LSM 710 equipped with an oil Plan-Apochromat 40x/1.3 DIC M27 objective) or light sheet microscope (live image, Zeiss Z.1 equipped with a water Plan-Apochromat 40x/1.0 DIC objective). For live imaging, imaging chamber was maintained at $37^{\circ} \mathrm{C}$ temperature, $5 \% \mathrm{CO}_{2}$ and supplemented with ENR media made with phenol red-free DMEM/F12. Three-dimension reconstruction was performed using Arivis Vision 4D. 3.0.1 software. For Figure 1D and video S2, the image was denoised using median filter (radius 1) followed by background correction.

\section{Rab11DN and Rab7DN vector construction}

Rab11DN and Rab7DN were generated by mutagenesis PCR from the pCMV-intron myc Rab11WT (Addgene \#46785) and pCMV-SPORT6-Rab7, respectively.

Primers used for Rab11DN are: 5'-GTGTTGGAAAGAACAACCTCCTGTCTCGATTTA-3' \& 5'-GACAGGAGGTTGTTCTTTCCAACACCAGAATC-3'. Primers used for Rab7DN are: 5'- CTGGTGTTGGAAAGAACTCTCTCATGAACCAG -3' \& 5'CTGGTTCATGAGAGAGTTCTTTCCAACACCAG -3'. DN constructs were cloned into the multiple cloning site I (MCSI) and mCerulean sequence was cloned into the MCS II of Tet- 
On ${ }^{\circledR}$ 3G Inducible Expression System (Bicistronic Version, pTRE3G-IRES, Takara \# 631166)

\section{Lentivirus production and concentration}

Lentivirus particle containing tet-activator was purchased from Takara (\#631311). Lentivirus containing inducible mycRab11DN-mCer and Rab7DN-mCer constructs were produced using calcium phosphate transfection in HEK293T cells (Takara \# 631312, user protocol). $2^{\text {nd }}$ generation lentiviral plasmids psPAX2 and pMD2.G were used (Addgene \#12260, \#12259). Lentivirus was concentrated with PEG-it ${ }^{\mathrm{TM}}$ (System Bioscience, \# LV810A-1, user protocol).

\section{Organoid transduction}

Organoids were transduced with lentivirus using the method modified from Maru et al., 2016 and Van Lidth de Jeude et al., 2015 [11, 12]. Briefly, $1^{\text {st }}$ generation of organoids from the crypts were passed with ENR medium containing Wnt3a, CHIR99021 and Nicotinamide to enrich stem cell population. 2-3 days later when the organoids display spheroid morphology with few dead cells in the lumen, organoids were mechanically broken down and trypsinized to single cells. Cells were washed and supplemented with the Lentivirus concentrate in a final concentration of $1 \mathrm{X}$ ENR media containing Wnt 3a, CHIR99021, Nicotinamide, TransDuxMAX ${ }^{\mathrm{TM}}$ with enhancer. Cells and virus mixture were incubated at $37^{\circ} \mathrm{C}$ water bath for around 1 hour, distributed to a matrigel-coated 24 well plates, incubated in the $37^{\circ} \mathrm{C}$ incubator for overnight. The next day, as live cells settle on the coated matrigel, supernatant containing virus and dead cell debris was carefully removed and fresh matrigel was added to form a sandwich having the live cells in the center of the two layers of the matrigel. ENR medium containing Wnt3a, CHIR99021 and Nicotinamide (without TransDuxMAX ${ }^{\mathrm{TM}}$ ) was supplied for 2 more days. A final concentration of $1 \mu \mathrm{g} / \mathrm{ml}$ puromycin and $100 \mu \mathrm{g} / \mathrm{ml}$ geneticin (neomycin) were added to select for the successful transduction with pTRE3G-DN mutant-IRES;mCerulean and tet-activator, respectively, until the transduced stem cells form small visible organoids. Media was returned to regular ENR media containing three antibiotics (pen-strep, puromycin and geneticin) and transduced organoids were cultured in presence of the three antibiotics throughout.

\section{QUANTIFICATION AND STATISTICAL ANALYSIS}

\section{Statistical Analysis}


555 All statistical analysis has been performed using Prism 8 (Graphpad). Details for statistical 556 tests used can be found in figure legends, including the number of replicates performed and 557 number of organoids analyzed for each condition and p-value 


\section{Video legends}

Video S1. Listeria crossing through intestinal organoid goblet cells. Related to Figure 1B and Figure S1D. 3D reconstruction of an intraluminally microinjected organoid, fixed 1 hour post injection. $L m$ (time 00:00-00:15: green, endogenous GFP thus intracellular; time 00:1600:25: cyan, double-labelled, thus translocated, see methods), Ecad (white) and WGA (red) are indicated. 3D reconstruction (time 00:26-00:43, time 01:12-01:25) and optical section (time 00:44-01:11) of $L i$-GFP (InlA) intraluminally microinjected organoids, expressing membrane tomato and fixed 2 hours post injection. WGA (white) and nucleus (blue) are indicated.

\section{Video S2. Real-time imaging of Listeria translocation. Related to Figure 1D.}

Intraluminally microinjected organoids expressing membrane tomato were imaged every 6 minutes for 2 hours. First and last horizontal rotation shows initial and last time point (00:00:00 and 01:30:00), respectively. Bacterial translocation initiated between time point 8 and 9 (00:42:00 and 00:48:00) and ended between time point 15 and 16 (01:24:00 and 01:30:00). The white arrow indicates the bacterium being transcytosed.

\section{Video S3. Mucus-expelling goblet cells express luminally accessible Ecad. Related to}

Figure 1E, F. Organoids were fixed, embedded in the agar, sectioned, immunolabeled from the lumen without permeabilization (time 00:00-00:12) and with permeabilization (time 00:13-00:25). Ecad (green), WGA (red) and nucleus (blue) are indicated. Note that Ecad in the sectioned plane is exposed, thus accessible without permeabilization and stained throughout the cut plane. Goblet cell enlarged in Figure 1E is marked with an arrow.

\section{Video S4. Listeria translocation is impaired when Ecad endocytosis and microtubule} dynamics are inhibited. Related to Figure 2D, E. Luminally accessible Ecad in mucusexpelling goblet cells in dynasore-treated organoids (time 00:00-00:12) and in cholchicinetreated organoids (time 00:13-00:24). Apical intracellular Listeria in dynasore-treated organoid (time 00:25-00:36) and Listeria in the central part inside the goblet cell in cholchicine-treated organoids (time 00:37-00:48).

\section{Video S5. Listeria translocation is impaired in Rab11DN but not in Rab7DN-induced} organoids. Related to Figure 4B, C. Luminally accessible Ecad in mucus-expelling goblet cells in Rab7DN-induced organoids (time 00:00-00:12) and in Rab11DN-induced organoids 
593 (time 00:13-00:24). Listeria translocated across the goblet cells in Rab7DN-induced organoid 594 (time 00:25-00:44) and Listeria trapped in the basolateral pole of goblet cell in Rab11DN595 induced organoids (time 00:45-01:01). Listeria trapped in mucus inside the goblet cell is 596 indicated by an arrow.

597 


\section{References}

1. Lecuit, M. (2020). Listeria monocytogenes, a model in infection biology. Cell Microbiol 22, e13186.

2. Gaillard, J.L., Berche, P., Frehel, C., Gouin, E., and Cossart, P. (1991). Entry of $L$. monocytogenes into cells is mediated by internalin, a repeat protein reminiscent of surface antigens from gram-positive cocci. Cell 65, 1127-1141.

3. Mengaud, J., Ohayon, H., Gounon, P., Mege, R.M., and Cossart, P. (1996). E-cadherin is the receptor for internalin, a surface protein required for entry of $L$. monocytogenes into epithelial cells. Cell 84, 923-932.

4. Lecuit, M., Dramsi, S., Gottardi, C., Fedor-Chaiken, M., Gumbiner, B., and Cossart, P. (1999). A single amino acid in E-cadherin responsible for host specificity towards the human pathogen Listeria monocytogenes. EMBO J 18, 3956-3963.

5. Lecuit, M., Vandormael-Pournin, S., Lefort, J., Huerre, M., Gounon, P., Dupuy, C., Babinet, C., and Cossart, P. (2001). A transgenic model for listeriosis: role of internalin in crossing the intestinal barrier. Science 292, 1722-1725.

6. Nikitas, G., Deschamps, C., Disson, O., Niault, T., Cossart, P., and Lecuit, M. (2011). Transcytosis of Listeria monocytogenes across the intestinal barrier upon specific targeting of goblet cell accessible E-cadherin. J Exp Med 208, 2263-2277.

7. Le, T.L., Yap, A.S., and Stow, J.L. (1999). Recycling of E-cadherin: a potential mechanism for regulating cadherin dynamics. J Cell Biol 146, 219-232.

8. Bruser, L., and Bogdan, S. (2017). Adherens Junctions on the Move-Membrane Trafficking of E-Cadherin. Cold Spring Harb Perspect Biol 9.

9. Sato, T., Vries, R.G., Snippert, H.J., van de Wetering, M., Barker, N., Stange, D.E., van Es, J.H., Abo, A., Kujala, P., Peters, P.J., et al. (2009). Single Lgr5 stem cells build crypt-villus structures in vitro without a mesenchymal niche. Nature 459, 262265.

10. Koo, B.K., Stange, D.E., Sato, T., Karthaus, W., Farin, H.F., Huch, M., van Es, J.H., and Clevers, H. (2011). Controlled gene expression in primary Lgr5 organoid cultures. Nat Methods 9, 81-83.

11. Maru, Y., Orihashi, K., and Hippo, Y. (2016). Lentivirus-Based Stable Gene Delivery into Intestinal Organoids. Methods Mol Biol 1422, 13-21.

12. Van Lidth de Jeude, J.F., Vermeulen, J.L., Montenegro-Miranda, P.S., Van den Brink, G.R., and Heijmans, J. (2015). A protocol for lentiviral transduction and downstream analysis of intestinal organoids. J Vis Exp.

13. Schwank, G., and Clevers, H. (2016). CRISPR/Cas9-Mediated Genome Editing of Mouse Small Intestinal Organoids. Methods Mol Biol 1422, 3-11.

14. Yin, X., Farin, H.F., van Es, J.H., Clevers, H., Langer, R., and Karp, J.M. (2014). Niche-independent high-purity cultures of Lgr5+ intestinal stem cells and their progeny. Nat Methods 11, 106-112.

15. McKinley, K.L., Stuurman, N., Royer, L.A., Schartner, C., Castillo-Azofeifa, D., Delling, M., Klein, O.D., and Vale, R.D. (2018). Cellular aspect ratio and cell division mechanics underlie the patterning of cell progeny in diverse mammalian epithelia. Elife 7.

16. Disson, O., Grayo, S., Huillet, E., Nikitas, G., Langa-Vives, F., Dussurget, O., Ragon, M., Le Monnier, A., Babinet, C., Cossart, P., et al. (2008). Conjugated action of two species-specific invasion proteins for fetoplacental listeriosis. Nature 455, 1114-1118.

17. de Lau, W., Kujala, P., Schneeberger, K., Middendorp, S., Li, V.S., Barker, N., Martens, A., Hofhuis, F., DeKoter, R.P., Peters, P.J., et al. (2012). Peyer's patch M 
cells derived from Lgr5(+) stem cells require SpiB and are induced by RankL in cultured "miniguts". Mol Cell Biol 32, 3639-3647.

18. Colony, P.C. (1996). Structural characterization of colonic cell types and correlation with specific functions. Dig Dis Sci 41, 88-104.

19. Johansson, M.E., and Hansson, G.C. (2012). Preservation of mucus in histological sections, immunostaining of mucins in fixed tissue, and localization of bacteria with FISH. Methods Mol Biol 842, 229-235.

20. Fischer, J., Uhlenbruck, G., Klein, P.J., Vierbuchen, M., and Fischer, R. (1984). Characterization of glycoconjugates of human gastrointestinal mucosa by lectins. II. Lectin binding to the isolated glycoproteins of normal and malignant gastric mucosa. $\mathrm{J}$ Histochem Cytochem 32, 690-696.

21. Fischer, J., Klein, P.J., Vierbuchen, M., Skutta, B., Uhlenbruck, G., and Fischer, R. (1984). Characterization of glycoconjugates of human gastrointestinal mucosa by lectins. I. Histochemical distribution of lectin binding sites in normal alimentary tract as well as in benign and malignant gastric neoplasms. J Histochem Cytochem 32, 681689.

22. Knoop, K.A., McDonald, K.G., McCrate, S., McDole, J.R., and Newberry, R.D. (2015). Microbial sensing by goblet cells controls immune surveillance of luminal antigens in the colon. Mucosal Immunol 8, 198-210.

23. Lecuit, M., Ohayon, H., Braun, L., Mengaud, J., and Cossart, P. (1997). Internalin of Listeria monocytogenes with an intact leucine-rich repeat region is sufficient to promote internalization. Infect Immun 65, 5309-5319.

24. Coelho, C., Brown, L., Maryam, M., Vij, R., Smith, D.F.Q., Burnet, M.C., Kyle, J.E., Heyman, H.M., Ramirez, J., Prados-Rosales, R., et al. (2019). Listeria monocytogenes virulence factors, including listeriolysin $\mathrm{O}$, are secreted in biologically active extracellular vesicles. J Biol Chem 294, 1202-1217.

25. Hunt, S.D., Townley, A.K., Danson, C.M., Cullen, P.J., and Stephens, D.J. (2013). Microtubule motors mediate endosomal sorting by maintaining functional domain organization. J Cell Sci 126, 2493-2501.

26. Desclozeaux, M., Venturato, J., Wylie, F.G., Kay, J.G., Joseph, S.R., Le, H.T., and Stow, J.L. (2008). Active Rab11 and functional recycling endosome are required for E-cadherin trafficking and lumen formation during epithelial morphogenesis. American Journal of Physiology-Cell Physiology 295, C545-C556.

27. Langevin, J., Morgan, M.J., Rosse, C., Racine, V., Sibarita, J.B., Aresta, S., Murthy, M., Schwarz, T., Camonis, J., and Bellaiche, Y. (2005). Drosophila exocyst components Sec5, Sec6, and Sec15 regulate DE-cadherin trafficking from recycling endosomes to the plasma membrane. Developmental Cell 9, 365-376.

28. Palacios, F., Schweitzer, J.K., Boshans, R.L., and D'Souza-Schorey, C. (2002). ARF6GTP recruits Nm23-H1 to facilitate dynamin-mediated endocytosis during adherens junctions disassembly. Nat Cell Biol 4, 929-936.

29. de Beco, S., Gueudry, C., Amblard, F., and Coscoy, S. (2009). Endocytosis is required for E-cadherin redistribution at mature adherens junctions. Proc Natl Acad Sci U S A 106, 7010-7015.

30. Delevoye, C., Miserey-Lenkei, S., Montagnac, G., Gilles-Marsens, F., PaulGilloteaux, P., Giordano, F., Waharte, F., Marks, M.S., Goud, B., and Raposo, G. (2014). Recycling endosome tubule morphogenesis from sorting endosomes requires the kinesin motor KIF13A. Cell Rep 6, 445-454.

31. Meng, W., Mushika, Y., Ichii, T., and Takeichi, M. (2008). Anchorage of microtubule minus ends to adherens junctions regulates epithelial cell-cell contacts. Cell 135, 948959. 
32. Veiga, E., Guttman, J.A., Bonazzi, M., Boucrot, E., Toledo-Arana, A., Lin, A.E., Enninga, J., Pizarro-Cerda, J., Finlay, B.B., Kirchhausen, T., et al. (2007). Invasive and adherent bacterial pathogens co-Opt host clathrin for infection. Cell Host Microbe 2, 340-351.

33. Macia, E., Ehrlich, M., Massol, R., Boucrot, E., Brunner, C., and Kirchhausen, T. (2006). Dynasore, a cell-permeable inhibitor of dynamin. Dev Cell 10, 839-850.

34. Taylor, E.W. (1965). The Mechanism of Colchicine Inhibition of Mitosis. I. Kinetics of Inhibition and the Binding of H3-Colchicine. J Cell Biol 25, SUPPL:145-160.

35. Kessell, I., Holst, B.D., and Roth, T.F. (1989). Membranous intermediates in endocytosis are labile, as shown in a temperature-sensitive mutant. Proc Natl Acad Sci U S A 86, 4968-4972.

36. Damke, H., Baba, T., Warnock, D.E., and Schmid, S.L. (1994). Induction of mutant dynamin specifically blocks endocytic coated vesicle formation. J Cell Biol 127, 915934.

37. Henley, J.R., Krueger, E.W., Oswald, B.J., and McNiven, M.A. (1998). Dynaminmediated internalization of caveolae. J Cell Biol 141, 85-99.

38. Lock, J.G., and Stow, J.L. (2005). Rab11 in recycling endosomes regulates the sorting and basolateral transport of E-cadherin. Molecular Biology of the Cell 16, 1744-1755.

39. Woichansky, I., Beretta, C.A., Berns, N., and Riechmann, V. (2016). Three mechanisms control E-cadherin localization to the zonula adherens. Nat Commun 7, 10834.

40. Sonnichsen, B., De Renzis, S., Nielsen, E., Rietdorf, J., and Zerial, M. (2000). Distinct membrane domains on endosomes in the recycling pathway visualized by multicolor imaging of Rab4, Rab5, and Rab11. J Cell Biol 149, 901-914.

41. Ullrich, O., Reinsch, S., Urbe, S., Zerial, M., and Parton, R.G. (1996). Rab11 regulates recycling through the pericentriolar recycling endosome. J Cell Biol 135, 913-924.

42. Yu, S., Yehia, G., Wang, J., Stypulkowski, E., Sakamori, R., Jiang, P., HernandezEnriquez, B., Tran, T.S., Bonder, E.M., Guo, W., et al. (2014). Global ablation of the mouse Rab11a gene impairs early embryogenesis and matrix metalloproteinase secretion. J Biol Chem 289, 32030-32043.

43. Sobajima, T., Yoshimura, S., Iwano, T., Kunii, M., Watanabe, M., Atik, N., Mushiake, S., Morii, E., Koyama, Y., Miyoshi, E., et al. (2014). Rab11a is required for apical protein localisation in the intestine. Biol Open 4, 86-94.

44. Palacios, F., Tushir, J.S., Fujita, Y., and D'Souza-Schorey, C. (2005). Lysosomal targeting of E-cadherin: a unique mechanism for the down-regulation of cell-cell adhesion during epithelial to mesenchymal transitions. Mol Cell Biol 25, 389-402.

45. Ettayebi, K., Crawford, S.E., Murakami, K., Broughman, J.R., Karandikar, U., Tenge, V.R., Neill, F.H., Blutt, S.E., Zeng, X.L., Qu, L., et al. (2016). Replication of human noroviruses in stem cell-derived human enteroids. Science 353, 1387-1393.

46. Lamers, M.M., Beumer, J., van der Vaart, J., Knoops, K., Puschhof, J., Breugem, T.I., Ravelli, R.B.G., Paul van Schayck, J., Mykytyn, A.Z., Duimel, H.Q., et al. (2020).

SARS-CoV-2 productively infects human gut enterocytes. Science.

47. Forbester, J.L., Goulding, D., Vallier, L., Hannan, N., Hale, C., Pickard, D., Mukhopadhyay, S., and Dougan, G. (2015). Interaction of Salmonella enterica Serovar Typhimurium with Intestinal Organoids Derived from Human Induced Pluripotent Stem Cells. Infect Immun 83, 2926-2934.

48. Heo, I., Dutta, D., Schaefer, D.A., Iakobachvili, N., Artegiani, B., Sachs, N., Boonekamp, K.E., Bowden, G., Hendrickx, A.P.A., Willems, R.J.L., et al. (2018). Modelling Cryptosporidium infection in human small intestinal and lung organoids. Nat Microbiol 3, 814-823. 
49. Lecuit, M., Hurme, R., Pizarro-Cerda, J., Ohayon, H., Geiger, B., and Cossart, P. (2000). A role for alpha-and beta-catenins in bacterial uptake. Proc Natl Acad Sci U S A $97,10008-10013$.

50. Bonazzi, M., Veiga, E., Pizarro-Cerda, J., and Cossart, P. (2008). Successive posttranslational modifications of E-cadherin are required for InlA-mediated internalization of Listeria monocytogenes. Cell Microbiol 10, 2208-2222.

51. Sousa, S., Cabanes, D., El-Amraoui, A., Petit, C., Lecuit, M., and Cossart, P. (2004). Unconventional myosin VIIa and vezatin, two proteins crucial for Listeria entry into epithelial cells. J Cell Sci 117, 2121-2130.

52. Sousa, S., Cabanes, D., Bougneres, L., Lecuit, M., Sansonetti, P., Tran-Van-Nhieu, G., and Cossart, P. (2007). Src, cortactin and Arp2/3 complex are required for E-cadherinmediated internalization of Listeria into cells. Cell Microbiol 9, 2629-2643.

53. Sousa, S., Cabanes, D., Archambaud, C., Colland, F., Lemichez, E., Popoff, M., Boisson-Dupuis, S., Gouin, E., Lecuit, M., Legrain, P., et al. (2005). ARHGAP10 is necessary for alpha-catenin recruitment at adherens junctions and for Listeria invasion. Nat Cell Biol 7, 954-960.

54. Tilney, L.G., and Portnoy, D.A. (1989). Actin filaments and the growth, movement, and spread of the intracellular bacterial parasite, Listeria monocytogenes. J Cell Biol 109, 1597-1608.

55. Dramsi, S., Levi, S., Triller, A., and Cossart, P. (1998). Entry of Listeria monocytogenes into neurons occurs by cell-to-cell spread: an in vitro study. Infect Immun 66, 4461-4468.

56. Dramsi, S., Biswas, I., Maguin, E., Braun, L., Mastroeni, P., and Cossart, P. (1995). Entry of Listeria monocytogenes into hepatocytes requires expression of inIB, a surface protein of the internalin multigene family. Mol Microbiol 16, 251-261.

57. Levraud, J.P., Disson, O., Kissa, K., Bonne, I., Cossart, P., Herbomel, P., and Lecuit, M. (2009). Real-time observation of Listeria monocytogenes-phagocyte interactions in living zebrafish larvae. Infect Immun 77, 3651-3660.

58. Balestrino, D., Hamon, M.A., Dortet, L., Nahori, M.A., Pizarro-Cerda, J., Alignani, D., Dussurget, O., Cossart, P., and Toledo-Arana, A. (2010). Single-cell techniques using chromosomally tagged fluorescent bacteria to study Listeria monocytogenes infection processes. Appl Environ Microbiol 76, 3625-3636.

59. Muzumdar, M.D., Tasic, B., Miyamichi, K., Li, L., and Luo, L. (2007). A global double-fluorescent Cre reporter mouse. Genesis 45, 593-605.

60. Mahe, M.M., Aihara, E., Schumacher, M.A., Zavros, Y., Montrose, M.H., Helmrath, M.A., Sato, T., and Shroyer, N.F. (2013). Establishment of Gastrointestinal Epithelial Organoids. Curr Protoc Mouse Biol 3, 217-240.

61. Waddell, A., Vallance, J.E., Hummel, A., Alenghat, T., and Rosen, M.J. (2019). IL-33 Induces Murine Intestinal Goblet Cell Differentiation Indirectly via Innate Lymphoid Cell IL-13 Secretion. J Immunol 202, 598-607.

62. Wu, D., Ahrens, R., Osterfeld, H., Noah, T.K., Groschwitz, K., Foster, P.S., Steinbrecher, K.A., Rothenberg, M.E., Shroyer, N.F., Matthaei, K.I., et al. (2011). Interleukin-13 (IL-13)/IL-13 receptor alpha1 (IL-13Ralpha1) signaling regulates intestinal epithelial cystic fibrosis transmembrane conductance regulator channeldependent Cl- secretion. J Biol Chem 286, 13357-13369.

63. van Es, J.H., van Gijn, M.E., Riccio, O., van den Born, M., Vooijs, M., Begthel, H., Cozijnsen, M., Robine, S., Winton, D.J., Radtke, F., et al. (2005). Notch/gammasecretase inhibition turns proliferative cells in intestinal crypts and adenomas into goblet cells. Nature 435, 959-963. 
64. Nigro, G., Hanson, M., Fevre, C., Lecuit, M., and Sansonetti, P.J. (2019). Intestinal Organoids as a Novel Tool to Study Microbes-Epithelium Interactions. Methods Mol Biol 1576, 183-194.

65. Johansson, M.E., Phillipson, M., Petersson, J., Velcich, A., Holm, L., and Hansson, G.C. (2008). The inner of the two Muc2 mucin-dependent mucus layers in colon is devoid of bacteria. Proc Natl Acad Sci U S A 105, 15064-15069. 
KEY RESOURCES TABLE

\begin{tabular}{|c|c|c|}
\hline REAGENT or RESOURCE & SOURCE & IDENTIFIER \\
\hline \multicolumn{3}{|l|}{ Antibodies and fluorescent dyes } \\
\hline Rat anti-E-cad (Eccd2) & Takara & \#M108 \\
\hline Rabbit anti Rab7 & Sigma & R4779 \\
\hline Rabbit antisera against Listeria monocytogenes & {$[55]$} & R11 \\
\hline Mouse IgG1 anti-myc (71D10) & Cell signaling & $\# 2278$ \\
\hline WGA-conjugated with Alexa Fluor 647 & Invitrogen & W32466 \\
\hline Hoechst 33342 & Invitrogen & $\mathrm{H} 3570$ \\
\hline Goat anti-Rat Alexa Fluor 546 & Invitrogen & \#A-11081 \\
\hline Goat anti-Rabbit Alexa Fluor 405 & Invitrogen & \#A-31556 \\
\hline Goat anti-Mouse Alexa Fluor 405 & Invitrogen & \#A-31553 \\
\hline \multicolumn{3}{|l|}{ Bacterial and Virus Strains } \\
\hline$L m$ strain EGD & {$[56]$} & BUG600 \\
\hline EGD $\triangle i n l A$ & {$[56]$} & BUG 947 \\
\hline EGD $\Delta h l y$ & [57] & BUG 2132 \\
\hline EGD $\Delta a c t A$ & [57] & BUG 2140 \\
\hline$L i \mathrm{WT}$ & [55] & BUG 499 \\
\hline $\operatorname{Li}(\operatorname{Inl} \mathrm{A}+)$ & {$[23]$} & BUG 1489 \\
\hline$L i$-GFP $($ InlA +$)$ & This paper & MBHL 366 \\
\hline rLV.EF1.Tet3G-9 & Takara & 631311 \\
\hline \multicolumn{3}{|l|}{ Chemicals, Peptides, and Recombinant Proteins } \\
\hline N2 Supplement & Gibco Invitrogen & $\# 17502048$ \\
\hline B27 Supplement & Gibco Invitrogen & $\# 17504044$ \\
\hline N-Acetylcystein & Sigma Aldrich & \#A9165-5G \\
\hline Human recombinant R-spondin 1 (final $500 \mathrm{ng} / \mathrm{ml}$ ) & R\&D systems & $\# 4645-\mathrm{RS} 250$ \\
\hline Mouse recombinant Noggin (final $100 \mathrm{ng} / \mathrm{ml}$ ) & Peprotech & $\# 250-38-20 u g$ \\
\hline Mouse recombinant EGF (final $50 \mathrm{ng} / \mathrm{ml}$ ) & Invitrogen & \#PMG8044 \\
\hline Y-27632 (final $10 \mathrm{uM}$ ) & Sigma Aldrich & $\# Y 0503-1 \mathrm{MG}$ \\
\hline Mouse recombinant Wnt3a (final $100 \mathrm{ng} / \mathrm{ml}$ ) & Millipore & \#GF160 \\
\hline Nicotinamide (final $10 \mathrm{mM}$ ) & Sigma Aldrich & \#N0636-100g \\
\hline CHIR99021 (final $10 \mathrm{uM}$ ) & Stemgent & $\# 248040004$ \\
\hline Doxycycline (final $2 \mathrm{ug} / \mathrm{ml}$ ) & Takara & $\# 631311$ \\
\hline Dynasore (final $80 \mathrm{uM}$ ) & Sigma & $324410-10 \mathrm{MG}$ \\
\hline Colchicine (final $10 \mathrm{ug} / \mathrm{ml}$ ) & Sigma & C3915 \\
\hline DATP (final $10 \mathrm{uM}$ ) & Stemgent & $\# 04-0041$ \\
\hline IL-13 (final $20 \mathrm{ng} / \mathrm{ml}$ ) & R\&D systems & \#413-ML-005 \\
\hline TransDux MAX ${ }^{\mathrm{TM}}$ & System Bioscience & LV860A-1 \\
\hline Matrigel & Corning & 356231 \\
\hline Cell recovery solution & $\mathrm{BD}$ & 354253 \\
\hline Advanced DMEM/F12 & Gibco Invitrogen & 12634010 \\
\hline DMEM/F12 phenol red-free & Gibco Invitrogen & 21041025 \\
\hline GlutaMAX & Gibco Invitrogen & 35050038 \\
\hline 1M Hepes & Gibco Invitrogen & 15630056 \\
\hline Penicilllin-streptomycin & Gibco Invitrogen & 15140163 \\
\hline Puromycin (final $1 \mathrm{ug} / \mathrm{ml}$ ) & Sigma & $540411-25 \mathrm{MG}$ \\
\hline
\end{tabular}




\begin{tabular}{|c|c|c|}
\hline Neomycin (Geneticin, final 1X) & Gibco Invitrogen & 10138031 \\
\hline \multicolumn{3}{|l|}{ Critical Commercial Assays } \\
\hline Calcium phosphate transfection kit & Takara & $\# 631312$ \\
\hline PEG-it ${ }^{\mathrm{TM}}$ Virus precipitation solution & System Bioscience & \# LV810A-1 \\
\hline \multicolumn{3}{|l|}{ Experimental Models: Cell Lines } \\
\hline HEK293T & $\overline{\text { ATCC }}$ & \#CRL-11268 \\
\hline L-WRN & ATCC & \#CRL-3276 \\
\hline \multicolumn{3}{|l|}{ Experimental Models: Organisms/Strains } \\
\hline Mouse (KI E16P) intestinal organoid & This paper and [16] & $\mathrm{N} / \mathrm{A}$ \\
\hline Mouse (mtd-Tmt; KI E16P) intestinal organoid & This paper and [6] & $\mathrm{N} / \mathrm{A}$ \\
\hline \multicolumn{3}{|l|}{ Oligonucleotides } \\
\hline $\begin{array}{lccr}\text { Primer } & \text { for } & \text { Rab11DN } & 5^{\prime}- \\
\text { GTGTTGGAAAGAACAACCTCCTGTCTCGAT } \\
\text { TTA-3' }\end{array}$ & This paper & $\mathrm{N} / \mathrm{A}$ \\
\hline $\begin{array}{lccr}\text { Primer } & \text { for } & \text { Rab11DN } & 5 '- \\
\text { GACAGGAGGTTGTTCTTTCCAACACCAGAA } \\
\text { TC-3' }\end{array}$ & This paper & N/A \\
\hline $\begin{array}{l}\text { Primer for } \quad \text { Rab7DN } \\
\text { CTGGTGTTGGAAAGAACTCTCTCATGAACC } \\
\text { AG -3' }\end{array}$ & This paper & $\mathrm{N} / \mathrm{A}$ \\
\hline 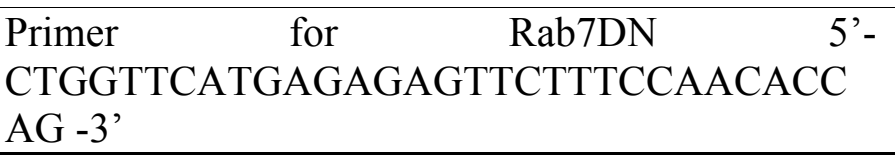 & This paper & N/A \\
\hline \multicolumn{3}{|l|}{ Recombinant DNA } \\
\hline $\mathrm{pAD}$ & {$[58]$} & $\mathrm{N} / \mathrm{A}$ \\
\hline psPAX2 & Addgene & $\# 12260$ \\
\hline pMD2.G & Addgene & $\# 12259$ \\
\hline pTREG3-IRES & Takara & $\# 631312$ \\
\hline pCMV-intron-mycRab11 & Addgene & $\# 46785$ \\
\hline pCMV-SPORT6-Rab7 & $\begin{array}{l}\text { Addgene and this } \\
\text { paper }\end{array}$ & N/A \\
\hline \multicolumn{3}{|l|}{ Software and Algorithms } \\
\hline Prism 8 & Graphpad & \\
\hline Arivis Vision4D 3.0. & Arivis & \\
\hline FIJI & ImageJ & \\
\hline ZEN 2014 SP1 & ZEISS & \\
\hline
\end{tabular}


A

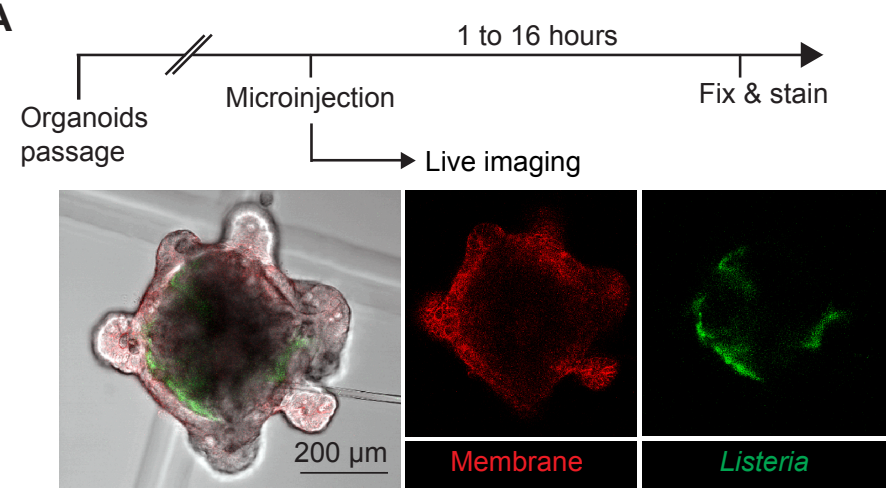

B
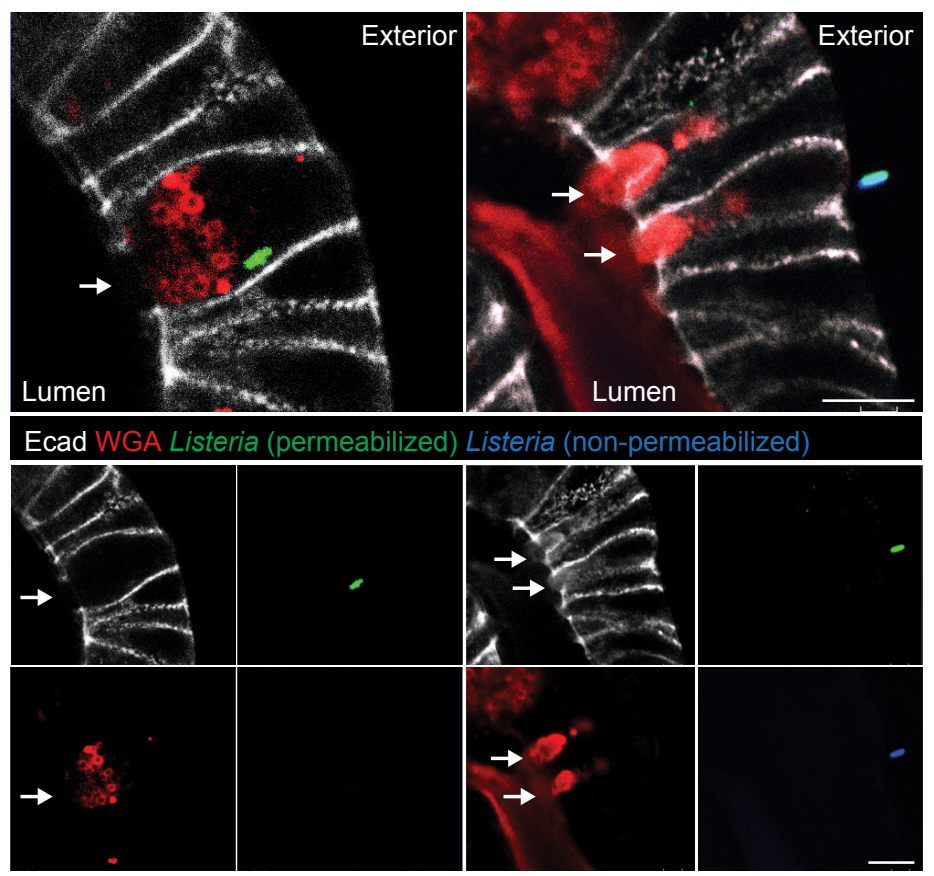

C

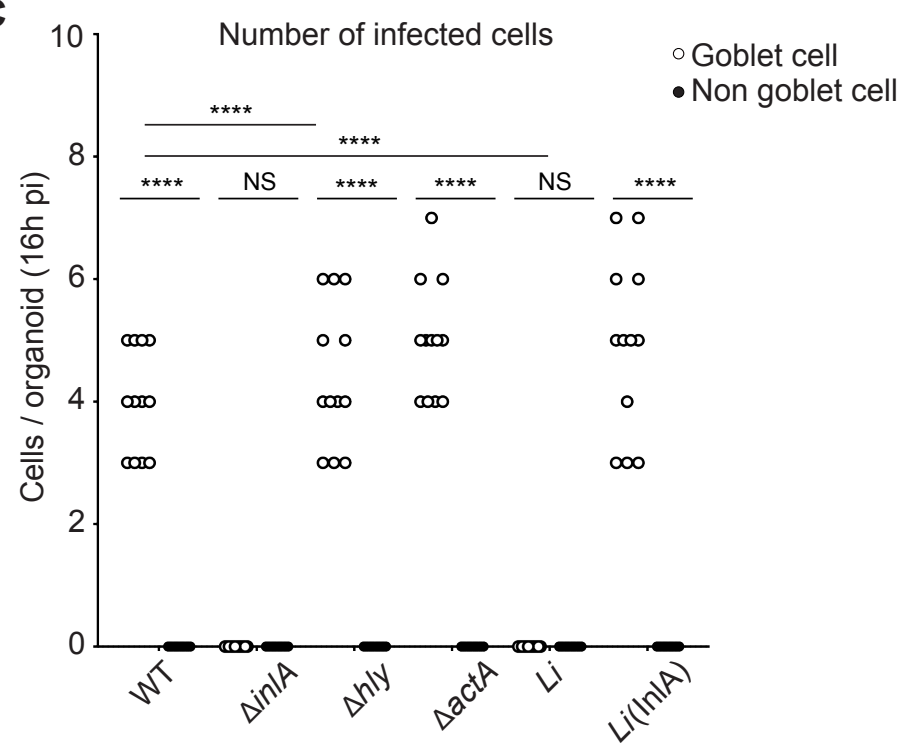

20 Number of bacteria associated with cells

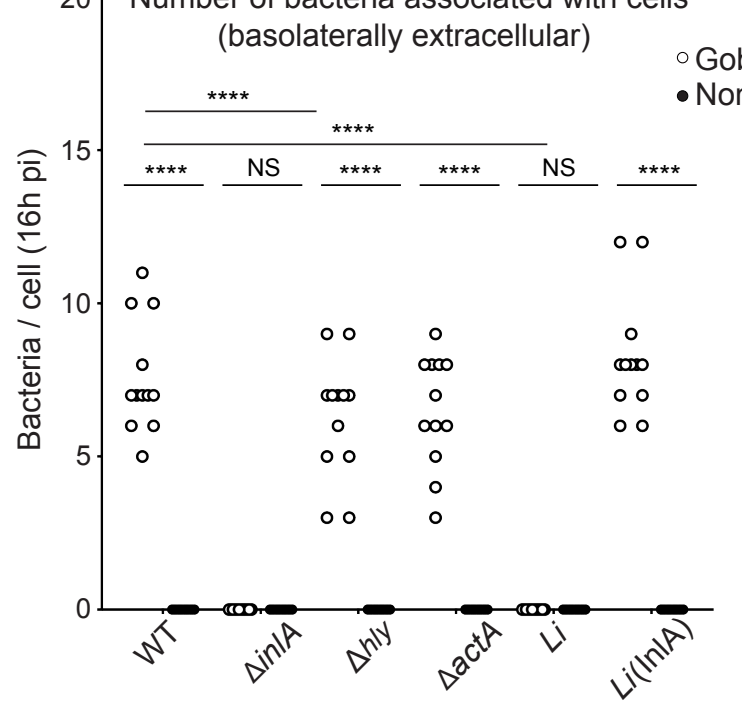

D

Time after microinjection (h:min:sec)

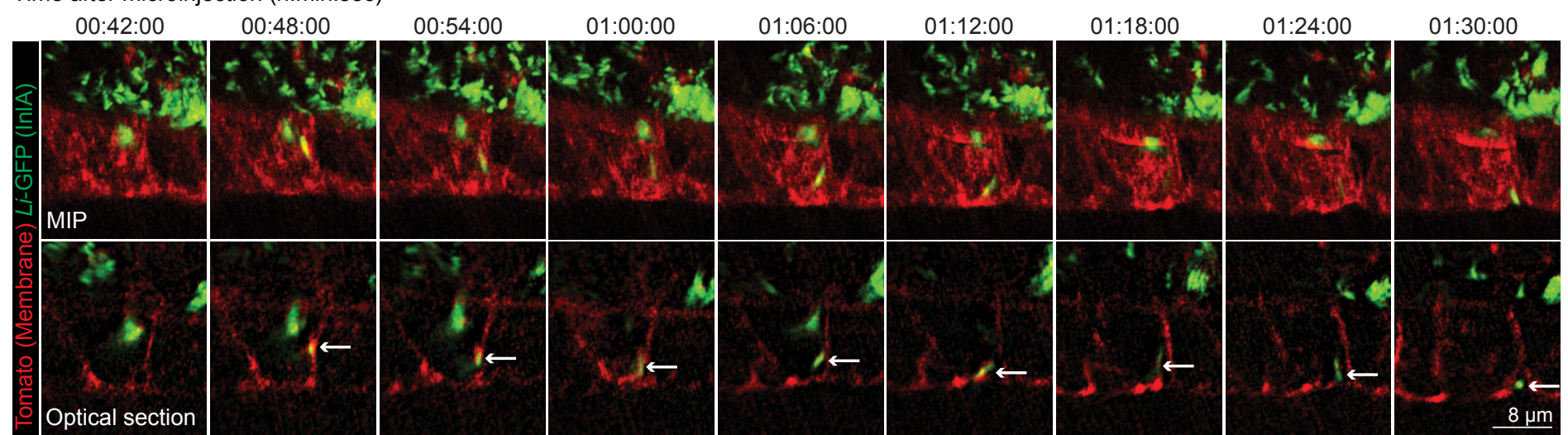

E

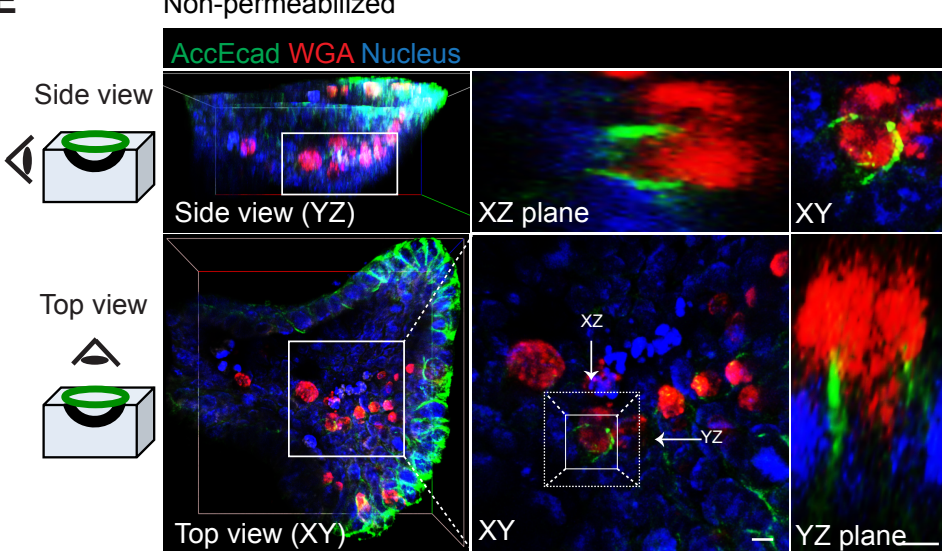

F

Permeabilized

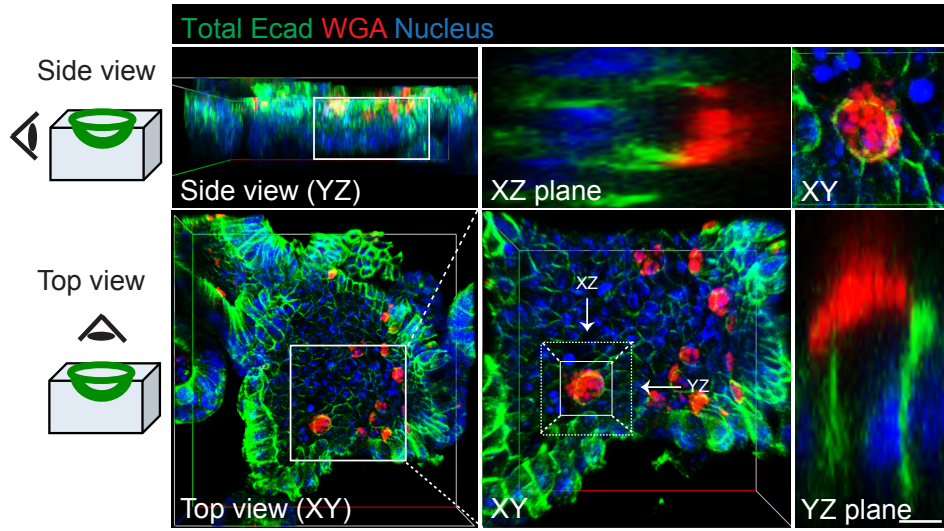


A

Double or sequential

Lentivirus 1 containing:

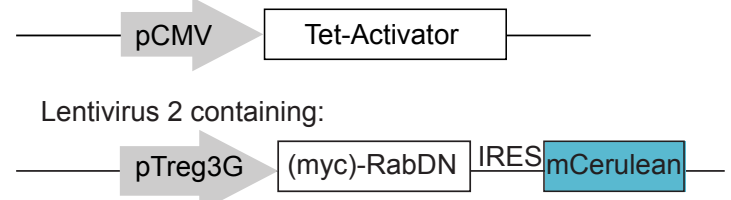

B

mycRab11DN-mCer
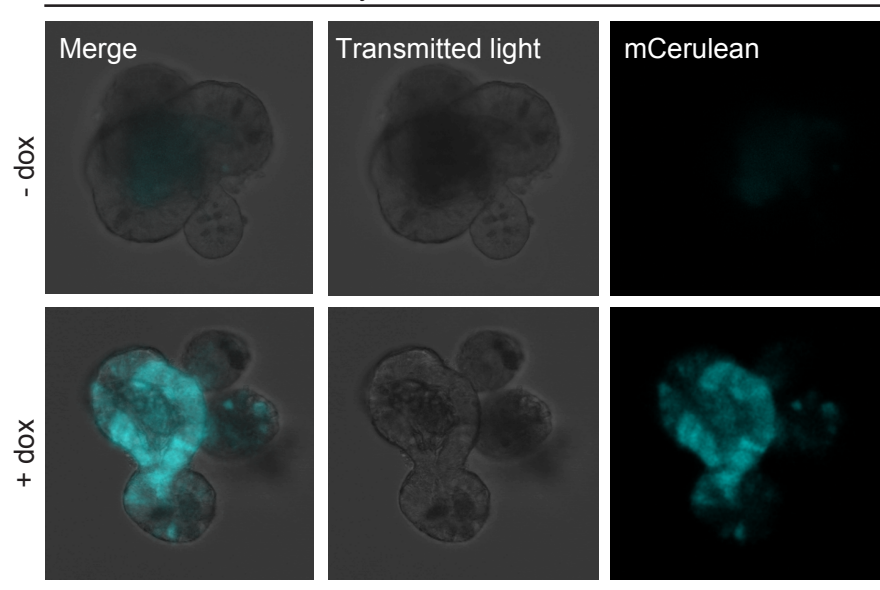

transduction

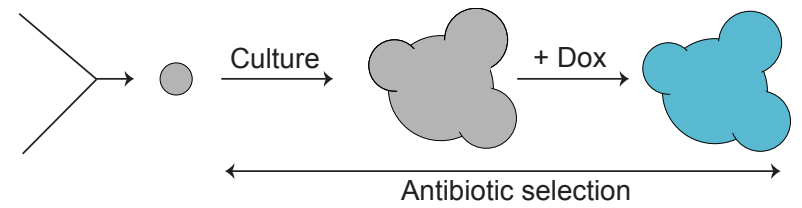

Rab7DN-mCer

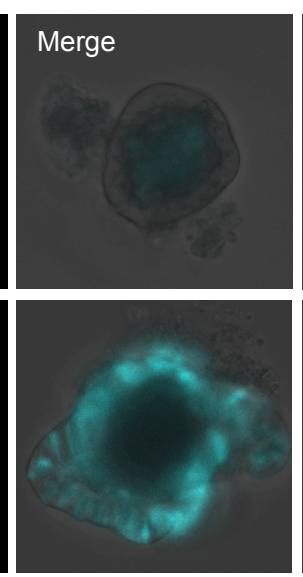

Transmitted light

mCerulean

$100 \mu \mathrm{m}$

C
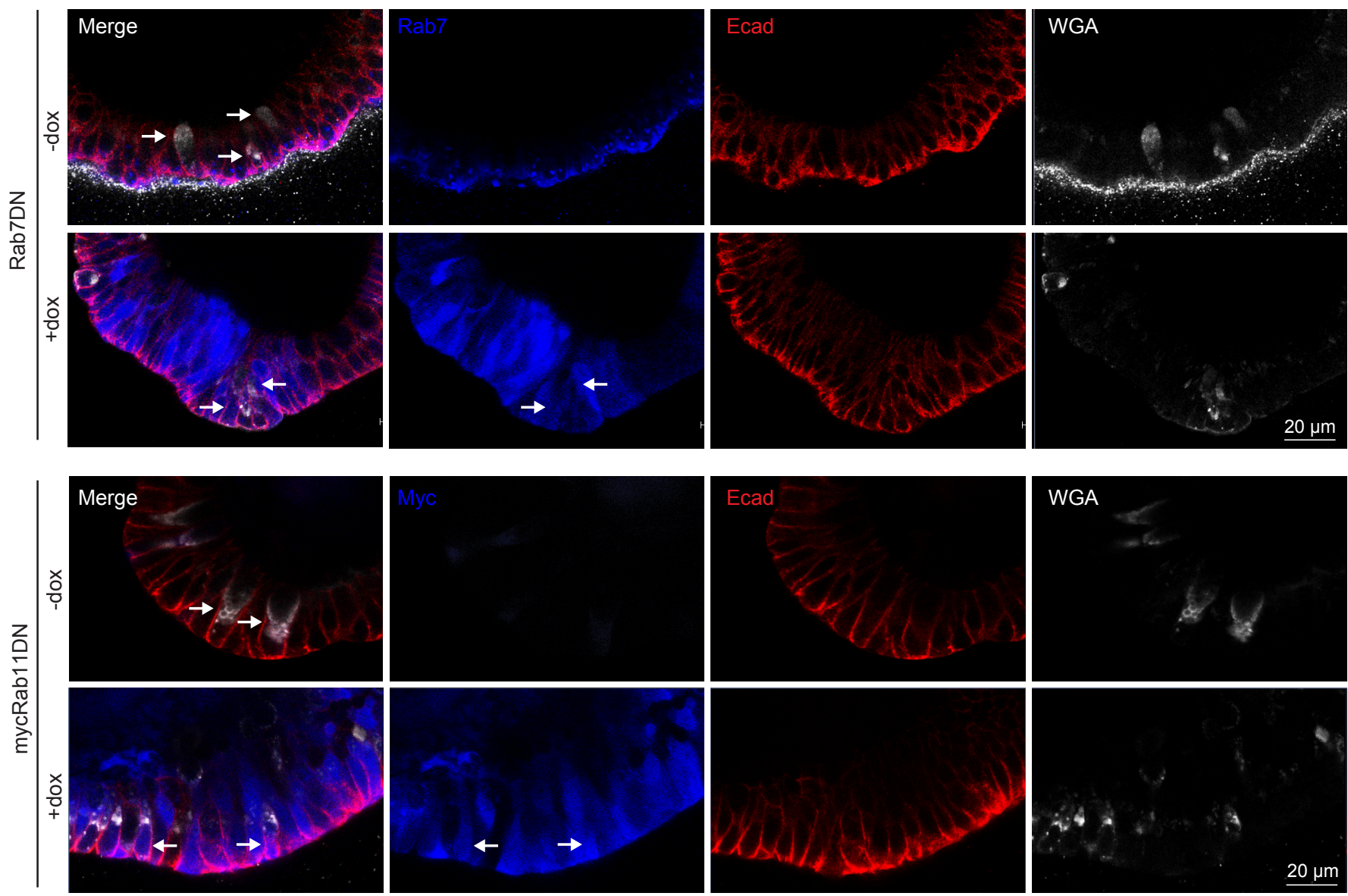
C

$\underset{\substack{\text { Organoids } \\ \text { passage }}}{\stackrel{1}{1}>16 \mathrm{hrs}} \stackrel{\text { Microinjection Fix \& stain }}{2}$

B
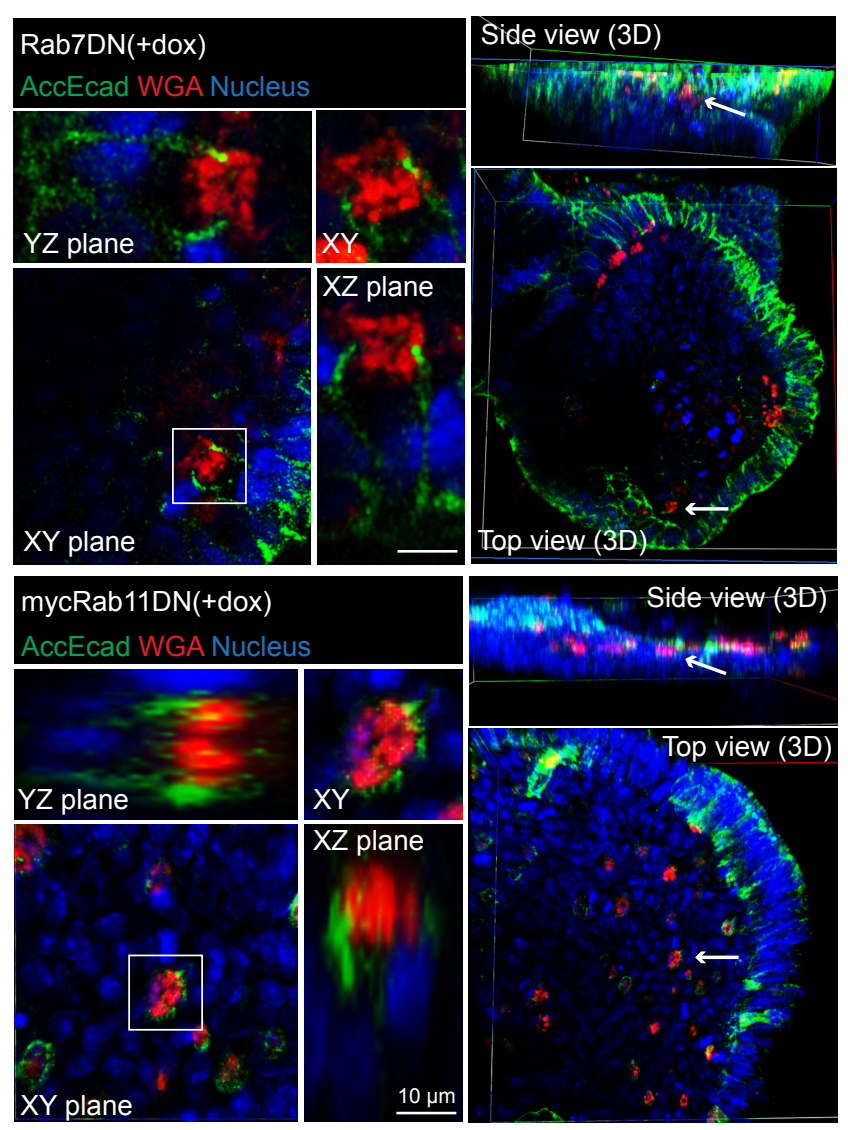

\section{Control (Transduced, non induced)}

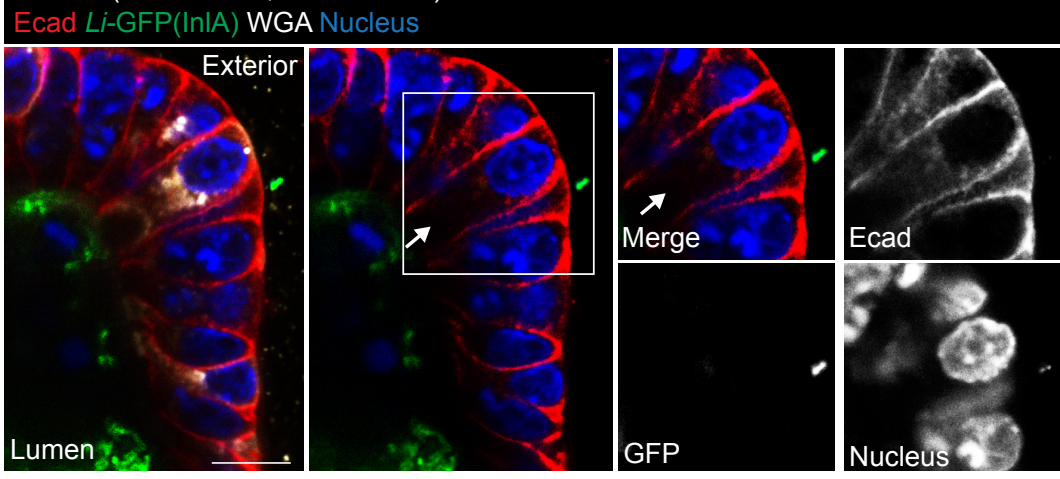

\section{Rab7DN (dox-induced)
Ecad Li-GFP(IIIA) WGA Nucleus}

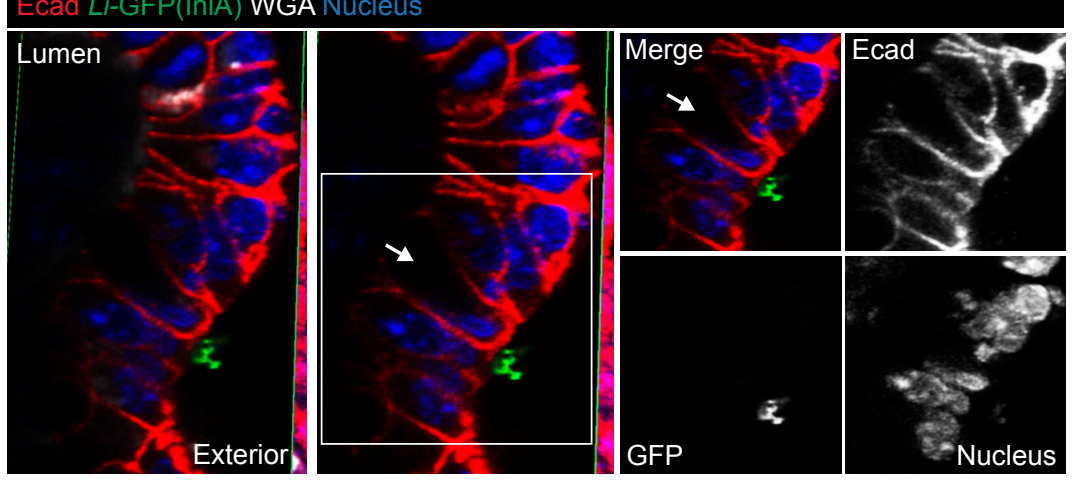

mycRab11DN (dox-induced)
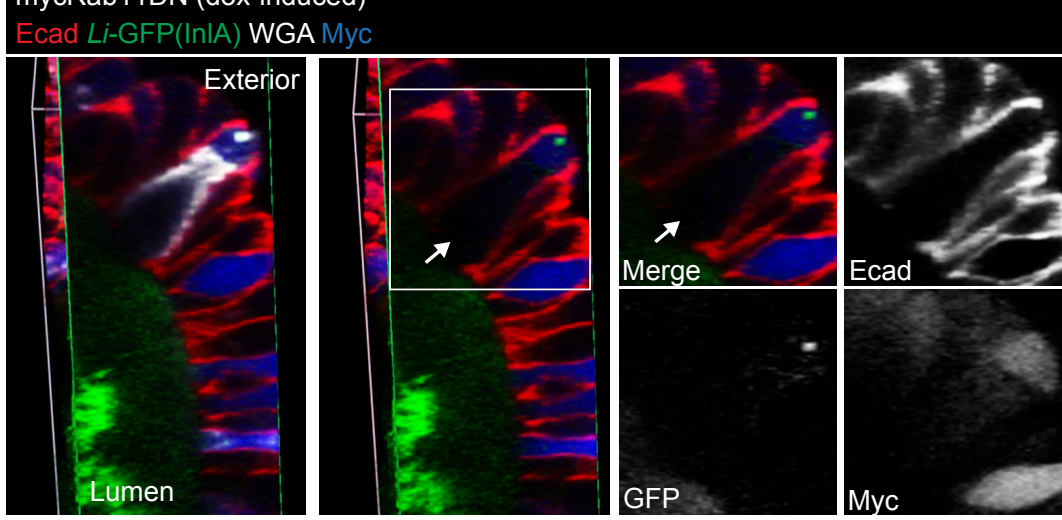

D

Number of cells associated with bacteria / organoid

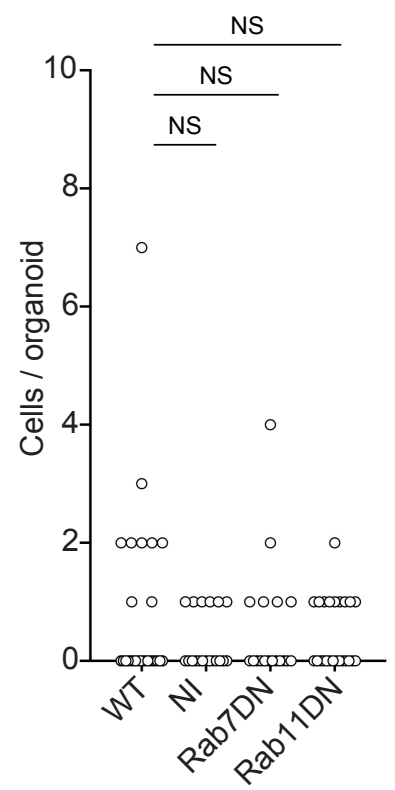

E Number of bacteria / organoid Basolaterally extracellular Apically-associated

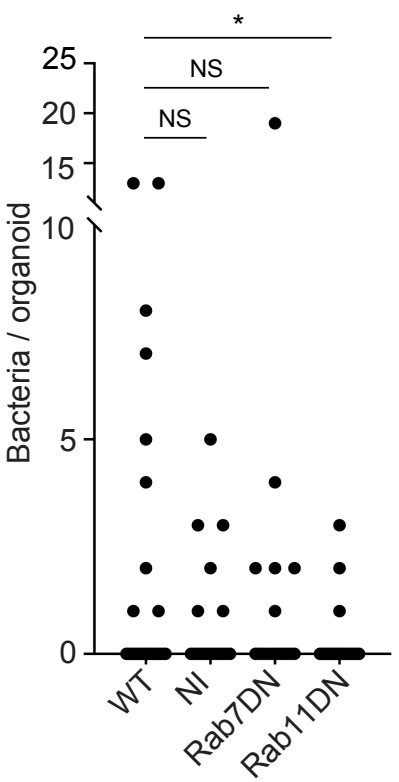

Intracellular (Central)

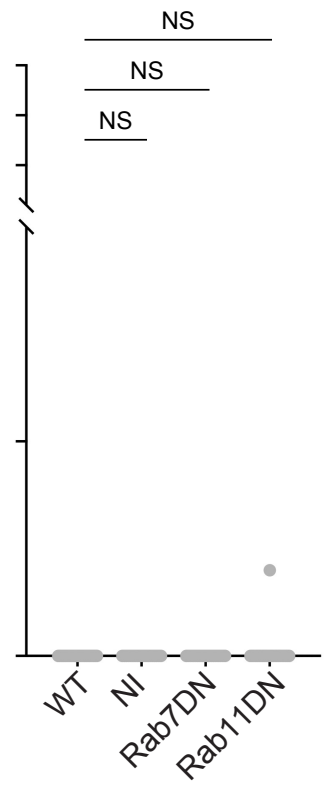

Intracellular (Basolateral)

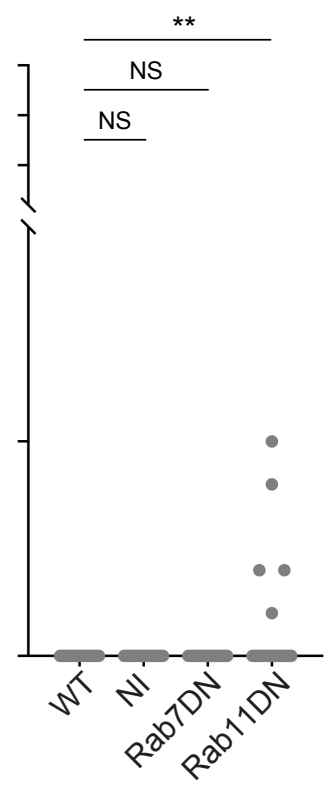


A

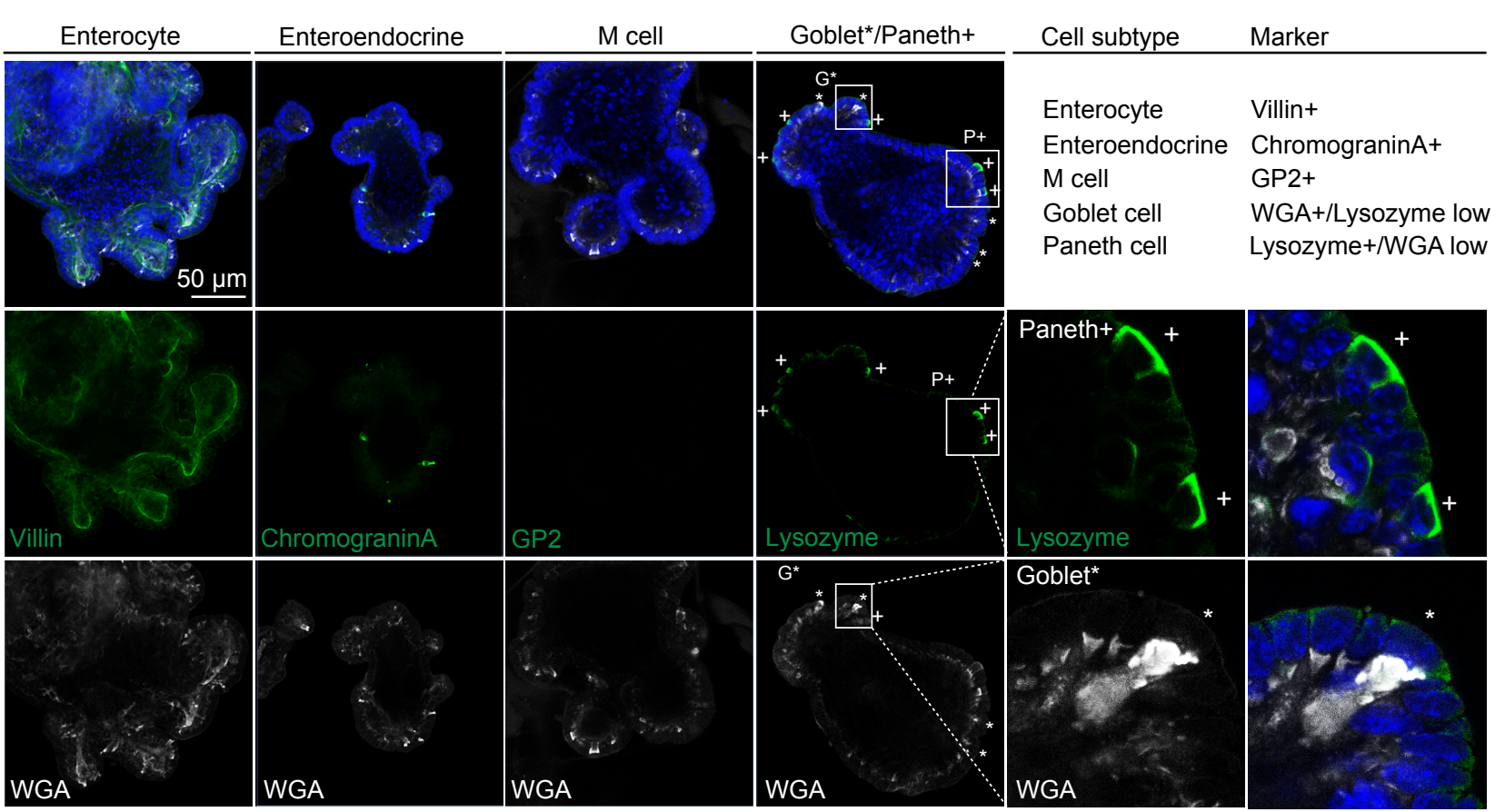

B

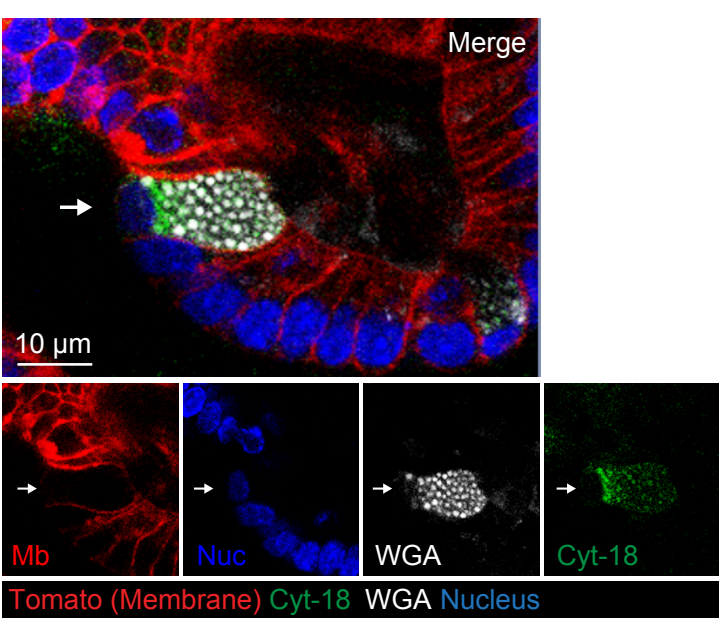

C

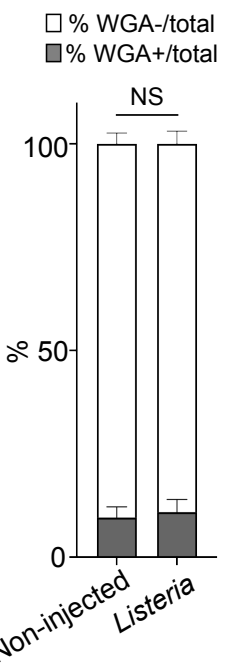

$16 \mathrm{~h}$ pi.

Listeria injected

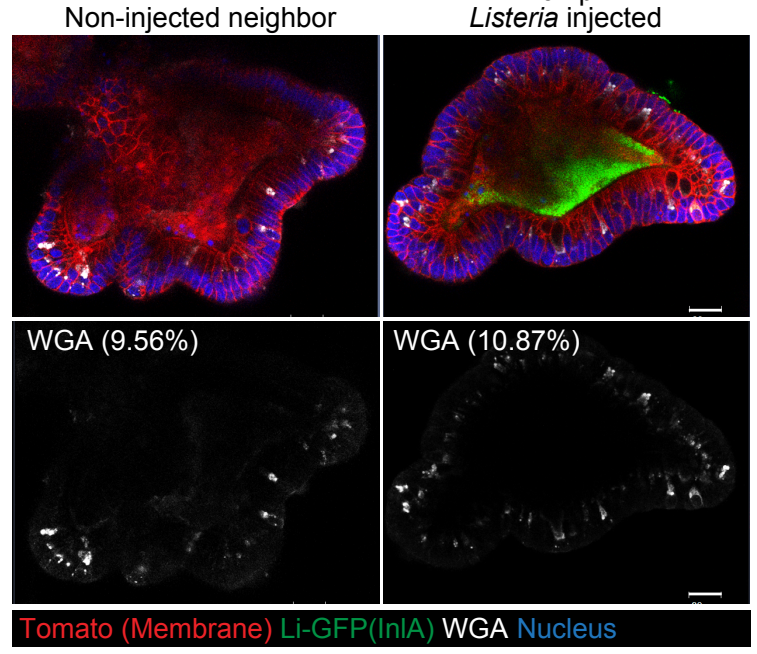

D
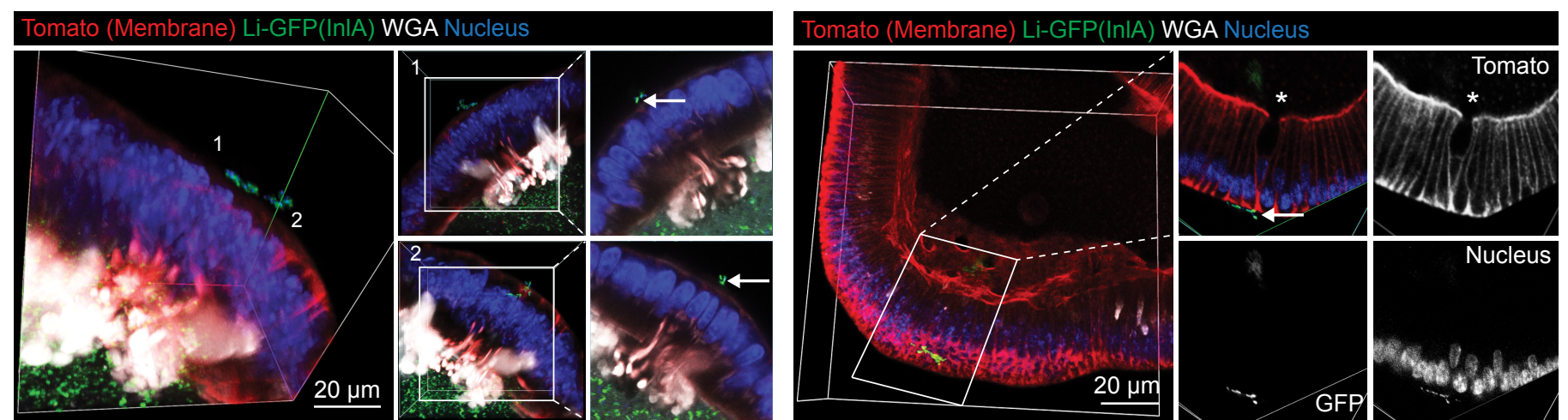

E

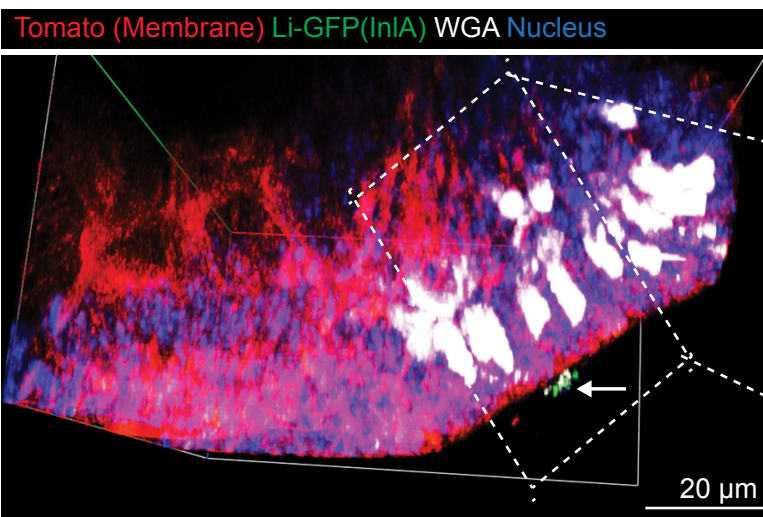

Optical section Optical section 
Figure S1. Expression of InlA by Listeria innocua allows translocation across the intestinal organoid epithelium. Related to Figure 1.

(A) Cell subtype heterogeneity in organoids. Enterocytes (villin ${ }^{+}$), enteroendocrine cells $\left(\right.$ chromogranin $\mathrm{A}^{+}$), goblet cells $\left(\mathrm{WGA}+/\right.$ Lysozyme $^{\text {low }}$ ), Paneth cells (Lysozyme ${ }^{+} / \mathrm{WGA}^{\text {low }}$ ) and M cells $\left(\mathrm{GP}^{+}\right)$are shown. Note that $\mathrm{M}$ cells are absent in intestinal organoids. (B) Goblet cell (arrow) labeled with WGA and cytokeratin-18. Besides the labeling, note that goblet cell displays cup-shaped morphology with apical side opened and/or squeezed nucleus. (C) \% of WGA ${ }^{+}$cell population in Listeria non-injected (left, control) and microinjected (right) organoids. Organoids were incubated for 16 hours post microinjection, non-injected control is from the same plate (non-injected neighboring organoids). Two-Way ANOVA test. NS: Not significant; $\mathrm{p}=0.61$. Confocal images of $L i$-GFP(InlA) (arrows) underneath the goblet cells after microinjection. 3D reconstruction and optical sections of boxed area are shown. Mucus material is not visible in the organoids on the right due to the fixation, thus goblet cells (asterisk) are identified based on typical goblet-shaped cellular morphology with opening of its apex. (E) Left: 3D reconstruction of an organoid showing translocated bacteria together with $\mathrm{WGA}^{+}$stained material, indicating that the bacteria exit the goblet cell with the mucus. Center \& Right: Optical section of the boxed area on the left. Mucus labeled with WGA that exited along with the bacteria is marked with an arrow. 
A

$\square$ WGA- cells $^{-}$

$\square \mathrm{WGA}^{+}$cells

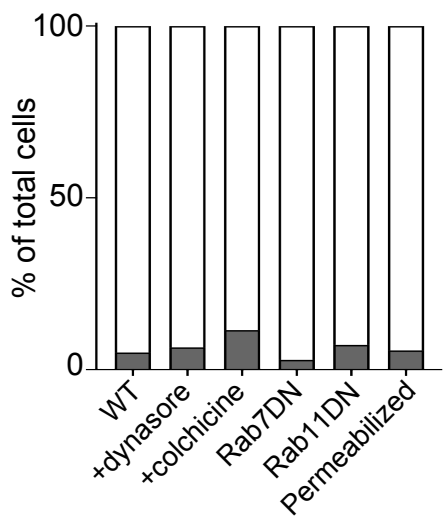

B $\square$ AccEcad $^{-}$cells

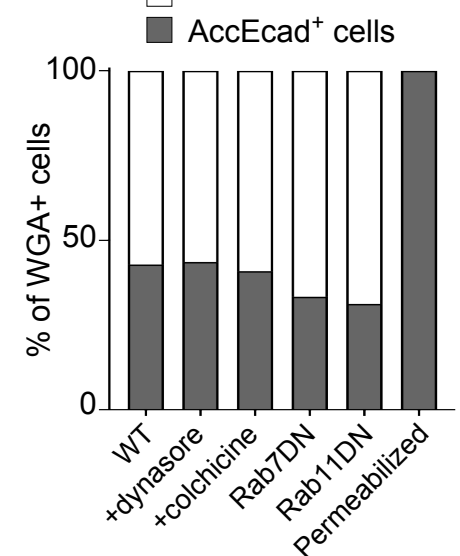

C

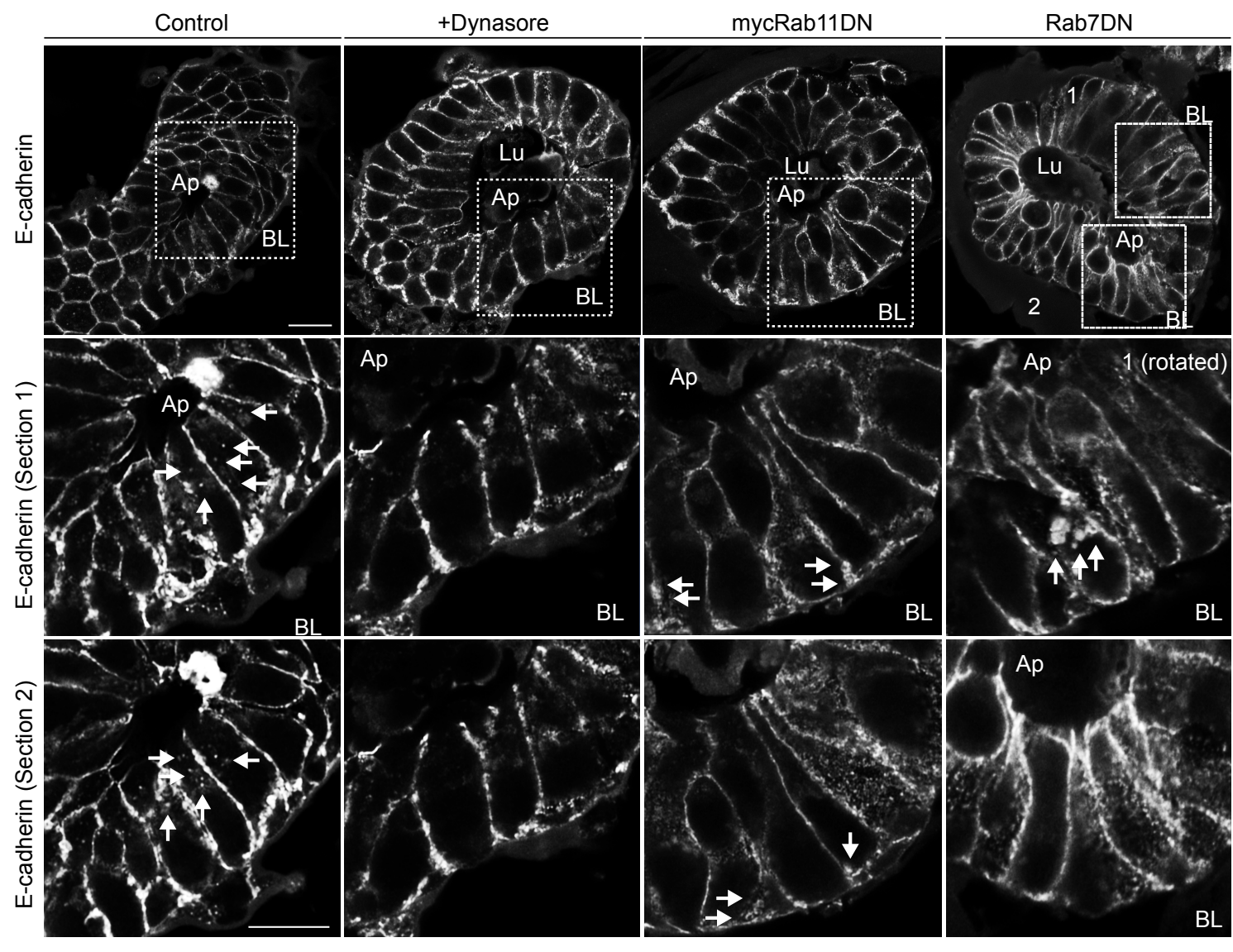

Listeria (EGD-GFP) injected, $16 \mathrm{~h}$ incubation

mycRab11DN-induced
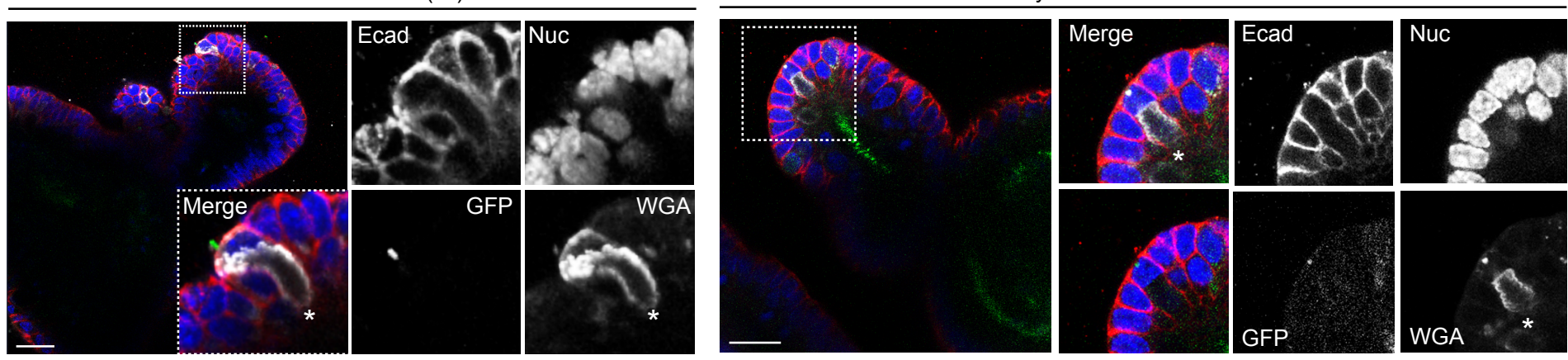

$\mathbf{F}$

Basolaterally extracellular

Apically-associated

Intracellular (Central)

Intracellular (Basolateral) with bacteria / organoid

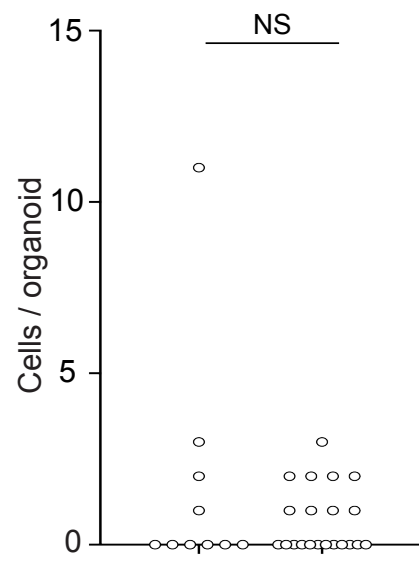

Transduced Rab11DN non-induced -induced

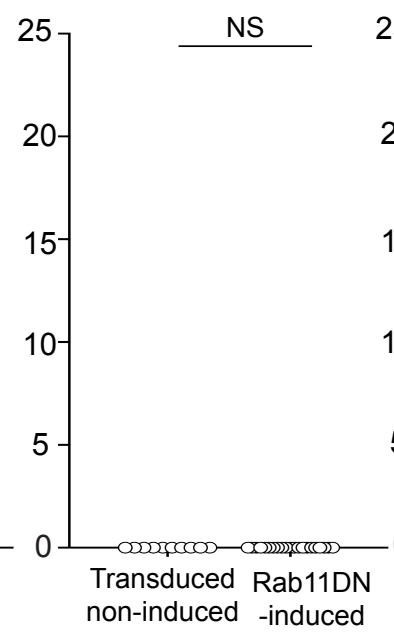

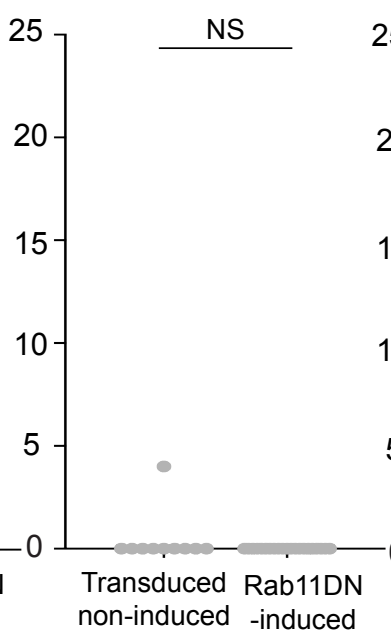

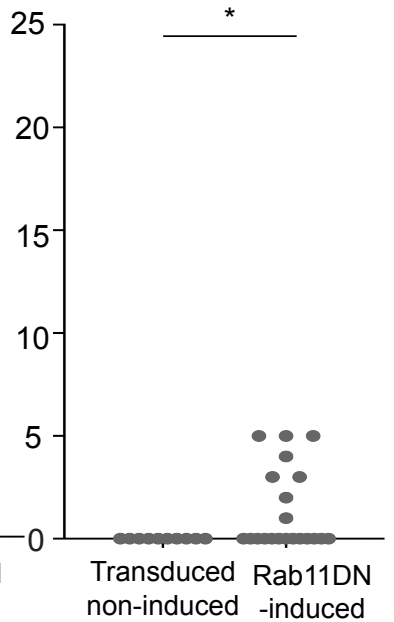


Figure S2. Inhibition of Ecad recycling pathway impairs $\mathbf{L m}$ transcytosis. Related to Figure

\section{2, 3 and 4 .}

(A) \% of goblet cells in organoids of indicated settings. Expelled mucus was identified with WGA staining. Organoids were briefly treated with DAPT and IL-13 to partially enrich goblet cell and mucus secretion (Method). (B) Distribution of luminally accessible Ecad on goblet cells in organoids with indicated treatments. (C) Ecad localization in indicated conditions. In control organoids, Ecad endocytic punctae can be seen in the cytosol ( $1^{\text {st }}$ column arrow), which is abolished when Dynasore is added ( $2^{\text {nd }}$ column). Ecad aggregates can be seen in Rab11DNexpressing organoids ( $3^{\text {rd }}$ column), suggesting that Ecad recycling/release is perturbed. Ecad in Rab7DN-expressing organoids are observed in big cytosolic aggregates (box 1) or dispersed cytosolic punctae (box 2), indicating that Ecad degradation is perturbed. Scale bar, $20 \mu \mathrm{m}$. (D) Organoids microinjected with WT Listeria were incubated for 16 hours in presence of doxycycline to induce DN protein. While Listeria translocates across the goblet cell in transduced, non-induced control (NI, left), Listeria is trapped at the basal pole inside the goblet cell in Rab11DN induced organoids (right). Goblet cells are marked with a star. Scale bar, $20 \mu \mathrm{m}$. (E) Quantification of number of cells associated with bacteria per organoids. Mann-Whitney test. NS: not significant. (F) Quantification of number of bacteria per organoids in indicated location. Counts were performed in 10 non-induced and 21 Rab11DN organoids. Mann-Whitney test. NS: non significant; $*: \mathrm{p}<0.05$. 


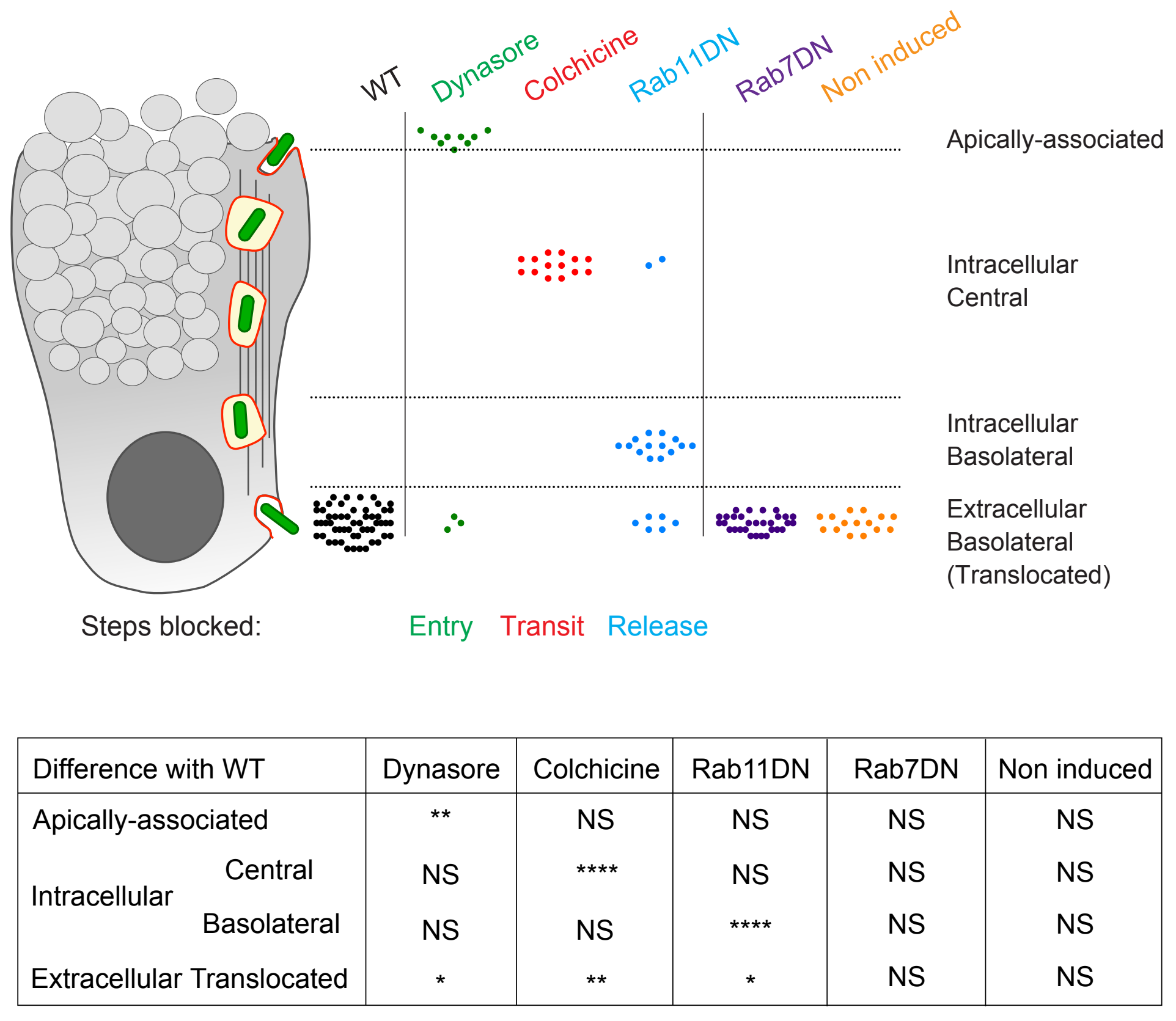


Figure S3. Molecular mechanism involved in Listeria transcytosis across the goblet cell.

\section{Related to Figure 2 and 4.}

Top: Graphical illustration combining the results of microinjection, with the total number of bacteria counted in each condition of organoids. Rab7DN-induced and transduced but noninduced organoids display basolaterally extracellular bacteria as WT organoids. This indicates that bacteria translocate across the organoid epithelium independently of Rab7-mediated Ecad degradation. Inhibition of dynamin-mediated endocytosis in organoids by dynasore leads to significantly increased number of bacteria that are apically associated to the goblet cells, but significant decrease in the number of translocated bacteria. This indicates that Ecad endocytosis is involved in the step of bacterial entry. Microtubule dynamics inhibition by colchicine also leads to significant decrease of translocated bacteria counts, but significant increase of intracellular bacteria that are located near the center of the cells. This indicates that bacteriacontaining vesicles transit via microtubule within the goblet cells. Rab11DN-induced organoids show significant increase in the number of intracellular bacteria located in the basolateral area of goblet cells, but significant decrease in the number of bacteria elsewhere, suggesting that functional Rab11 is required in completing bacterial translocation. Bottom: Table summarizing the statistical significances. Kruskall Wallis test. Comparison to WT. NS: Not significant; *:

$\mathrm{p}<0.05 ; * *: \mathrm{p}<0.01 ; * * * *: \mathrm{p}<0.0001$ 